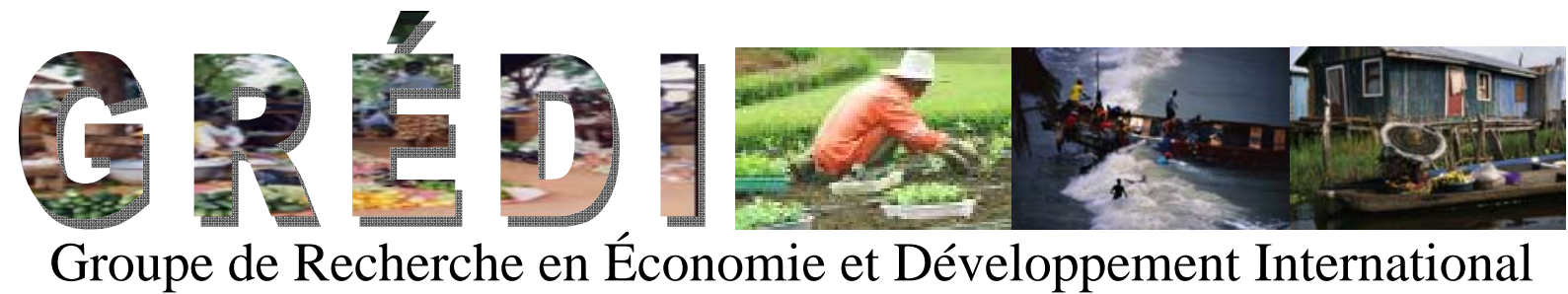

Cahier de recherche / Working Paper

08-16

On Financial Markets Incompleteness, Price Stickiness, and Welfare in a Monetary Union

Stéphane Auray

Aurélien Eyquem 


\title{
On Financial Markets Incompleteness, Price Stickiness, and Welfare in a Monetary Union *
}

\author{
Stéphane Auray ${ }^{\mathrm{a}, *}$, Aurélien Eyquem ${ }^{\mathrm{b}}$, \\ ${ }^{a}$ EQUIPPE (EA 4018), Universités Lille Nord de France (ULCO) \\ GREDI, Université de Sherbrooke and CIRPÉE, Canada. \\ ${ }^{\mathrm{b}}$ GATE (UMR 5824), Universités de Lyon \\ Ecole Normale Supérieure Lettres et Sciences Humaines, France \\ GREDI, Université de Sherbrooke, Canada.
}

This version: July 2009

\begin{abstract}
The paper builds a two-country model of a monetary union with home bias and price stickiness. Incompleteness of financial asset markets is allowed. In this environment, we derive the solution for optimal behavior by the monetary policymaker and show that welfare can be higher under incomplete markets than under complete markets. The argument is a secondbest one. In a monetary union with equal nominal rigidity across countries, optimal monetary policy stabilizes aggregate, union-wide inflation, but cannot fully stabilize the country-level inflation rates. Market incompleteness results in less volatility of the terms-of-trade (because part of the adjustment goes through the current account), and hence less volatile national inflation rates. Through this channel, welfare ends up being higher under incomplete markets. These results are also robust when nominal rigidity differs across countries and when the form of the monetary policy is modified.
\end{abstract}

Keywords: monetary union, asymmetric shocks, financial market incompleteness, price stickiness, welfare.

JEL Class.: E51, E58, F36, F41.

* Pierpaolo Benigno, Hafedh Bouakez, Gordon Fisher, Fabio Ghironi, Paul Gomme, Tatyana Koreshkova and Eric Van Wincoop and conference and seminar participants at several institutions provided helpful suggestions. A previous version of this paper was completed while Auray was visiting the department of economics at Concordia University, Montreal. He is grateful for their kind hospitality. The traditional disclaimer applies.

* Corresponding author. Email: stephane.auray@gmail.com 


\section{Introduction}

This paper measures the welfare costs/gains associated with incomplete financial markets in a monetary union with idiosyncratic productivity shocks and sticky prices. Completeness of financial markets usually yields important welfare gains by allowing agents to share risks perfectly among agents, countries and states of nature. As a counterpart, in multi-country models, relative prices are the favored external adjustment channel, which leads real exchange rates to be more volatile under complete than incomplete financial markets. This may not be a problem in a flexible-price environment. However, this excess of real exchange rate volatility may be costly in a second-best environment, i.e. characterized by idiosyncratic shocks, price stickiness and less policy instruments than targets, as in fixed exchange rates area or monetary unions. In this paper, we show that the costs arising from the excess of real exchange rate volatility under complete financial markets quantitatively exceed the welfare gains related to a better sharing of risks in a second-best environment.

Here, we have in mind the achievement of a monetary union in Europe, often seen as part of a process of integrating goods and financial markets. Financial markets integration is indeed often seen as a necessary step, as the loss of policy flexibility implied by monetary unification requires insurance mechanisms against country-specific shocks. The central result demonstrated in this paper states that achieving financial markets completeness in a second-best environment is not necessarily welfare improving. It therefore appears as an important warning against the simplistic and potentially misleading logic according to which policies aimed at deepening financial markets integration should be the priority when achieving monetary unification.

Formally, the paper builds on a two-country model of a currency area with sticky prices in the spirit of Benigno [2004] allowing for home bias in private consumption and financial markets incompleteness, as in Benigno [2007]. However, contrary to the latter, it is assumed that policymakers face a monetary policy trade-off. Indeed, Calvo contracts introduce a wedge between efficient (flexible prices) and sticky prices fluctuations in country-level labor efforts. As a result, arguments of the utility-based welfare measure that policymakers use to determine their policies include country-level inflation rate as standard arguments in addition to the standard terms-of-trade gap. The first-best equilibrium that actually replicates the flexible prices equilibrium is thus out of reach and the second-best equilibrium is characterized by a stabilization of aggregate inflation (as in Benigno [2004]) but also features some volatility of country-level inflation rates. As a consequence, even though financial markets incompleteness does not allow agents to smooth consumption optimally, it is associated with a lower volatility of the real exchange rate (driven by differences in country-level inflation rates), which implies welfare gains with respect to a situation of complete financial markets.

First, it is noticeable that this result is robust to various specifications of the monetary policy that the common Central Bank commits to. The result holds under (Ramsey) 
optimal monetary policy, optimal Taylor rules and simple Taylor-type rules. It is also robust to variations in parameterizations (risk-aversion, labor supply elasticity, asymmetric nominal rigidities). The key point in generating the result is the existence of the policy trade-off implied by idiosyncratic shocks, price stickiness and the limitation of instruments to conduct stabilization policies.

Second, our framework encompasses several standard results relative to the welfare gains of perfect risk-sharing in flexible-price environment. When prices are flexible (or when national monetary policies allow for country-level price stability equilibria), perfect risk-sharing is found to increase the welfare, as Benigno [2007] and Van Wincoop [1999]. A reduction in home bias in private consumption is also found to reduce significantly the welfare distance between complete and incomplete financial markets equilibria, as in Cole and Obstfeld [1991].

Third, the magnitude of welfare gains and losses remains small, in accordance with others studies in sticky-price environments (see for instance Gali and Monacelli [2005] and Faia [2007]). In average, under sticky prices, incomplete financial markets imply welfare gains corresponding to a $0.01-0.02 \%$ increase in permanent consumption for a constant labor effort. Under flexible prices, the welfare gains arising from perfect risk-sharing are equivalent to an average $0.005 \%$ increase in permanent consumption.

The remaining of the paper is structured as follows. Section 2 presents the model. Section 3 describes the dynamics of the model and the authorities' loss function. Section 4 determines the optimal (Ramsey) policy. Section 5 analyzes the dynamics of the model after an asymmetric productivity shock. Section 6 presents the welfare analysis under alternative financial markets structures and monetary policies, and presents to some robustness experiments. Conclusions are summarized in Section 7.

\section{A two-country model}

The model describes a two-country monetary union with a common Central Bank that controls the nominal interest rate. Each country is populated by a continuum of households of infinite life, an infinite number of firms that are specialized in the production of differentiated goods and a government. Goods markets are characterized by a home bias in consumption bundles and Calvo-staggered adjustment of prices. Financial market incompleteness is allowed.

\subsection{Households and financial markets}

In each country the representative household $j \in[0,1]$ of country $i \in\{h, f\}$ maximizes a welfare index, 


$$
\omega_{t}^{i}(j)=E_{0} \sum_{t=0}^{\infty} \beta^{t}\left\{\frac{C_{t}^{i}(j)^{1-\sigma}}{1-\sigma}-\frac{N_{t}^{i}(j)^{1+\psi}}{1+\psi}\right\},
$$

subject to the budget constraint, ${ }^{1}$

$$
B_{t}^{i}(j)-R_{t-1} B_{t-1}^{i}(j)=W_{t}^{i} N_{t}^{i}(j)+\Pi_{t}^{i}(j)-P_{t}^{i} C_{t}^{i}(j)-P_{i, t} A C_{t}^{i}(j)-T_{t}^{i}(j),
$$

and the transversality condition, $\lim _{T \rightarrow \infty} \Pi_{\tau=t}^{T} R_{\tau-1}^{-1} E_{t}\left\{B_{T}^{i}(j)\right\}=0$. In (1), the parameter $\beta$ is the subjective discount factor, $C_{t}^{i}(j)$ is the consumption bundle chosen by the representative household, $N_{t}^{i}(j)$ is its competitive labor supply, $\sigma$ is the coefficient of risk-aversion and $\psi^{-1}$ is the elasticity of labor supply. In (2), $W_{t}^{i}$ is the nominal wage in country $i$ for period $t, \Pi_{t}^{i}(j)=\int_{0}^{1} \Pi_{t}^{i}(k, j) d k$ is the profit paid by national firms to the representative national household $j . B_{t-1}^{i}(j)$ corresponds to the holding of the oneperiod nominal bond at the end of period $t-1$ denominated in units of the common currency which pays a gross nominal rate of interest $R_{t-1}$ between periods $(t-1)$ and $t, T_{t}^{i}(j)$ is a lump-sum tax paid by household $j$ to the national government of country $i$. Finally, $P_{t}^{i}$ is the consumer price index in country $i$ in period $t, P_{i, t}$ is the producer price index in country $i$ in period $t$ and $A C_{t}^{i}(j)$ is a portfolio adjustment cost paid in units of domestic goods.

In the case detailed above, the financial market of the monetary union is incomplete and households trade a one-period financial asset. Buying (resp. selling) bonds affects negatively (resp. positively) the individualized interest rate, so that: (i) agents have a strong incentive to return to their initial position in the long run; and (ii) agents belonging to a creditor country face lower nominal interest rates than agents in the debtor country. As underlined by Schmitt-Grohe and Uribe [2003], this assumption is a convenient way to balance the current account in the long run between union members while preserving its short-run dynamics. We impose a standard quadratic form for portfolio adjustment costs,

$$
A C_{t}^{i}(j)=\frac{\chi}{2}\left(B_{t}^{i}(j)-B^{i}(j)\right)^{2}
$$

where $B^{i}(j)$ is the steady state level of financial assets hold by agent $j$ in country $i$. Portfolio adjustment costs affect the Euler condition since,

$$
\frac{\beta R_{t}}{1+\chi P_{i, t}\left(B_{t}^{i}(j)-B^{i}(j)\right)} E_{t}\left\{\frac{P_{t}^{i} C_{t}^{i}(j)^{\sigma}}{P_{t+1}^{i} C_{t+1}^{i}(j)^{\sigma}}\right\}=1 .
$$

Eq.(3) highlights that creditor (respectively debtor) households face an incentive to increase (respectively decrease) their current consumption. This results in a faster return to their initial asset holdings.

1 The model features no money holdings, since money is endogenously supplied depending on the level of nominal interest rate. 
When markets are complete, agents are supposed to have access to a continuum of Arrow-Debreu securities. In this case, the risk-sharing condition holds and then the real marginal utility of consumption is the same among agents and across the monetary union,

$$
P_{t}^{h} C_{t}^{h}(j)^{\sigma}=P_{t}^{f} C_{t}^{f}(j)^{\sigma}, \forall t .
$$

Contrary to the case of incomplete financial markets, the measure of the current account that captures changes in asset quantities remains constant: insurance contracts are executed, deliveries are made, and net foreign assets move only to the extent that asset values change.

The labor supply function is standard and depends on the level of consumption and the real wage,

$$
N_{t}^{i}(j)^{\psi}=\frac{W_{t}^{i}}{P_{t}^{i} C_{t}^{i}(j)^{\sigma}}
$$

We assume home bias in final consumption bundles (see, for instance Canzoneri and Henderson [1991] and more recently Corsetti [2006]). The consumption bundle of consumer $j$ living in country $i, C_{t}^{i}(j)$, is,

$$
C_{t}^{i}(j)=\left[\left(1-\alpha_{i}\right)^{\frac{1}{\mu}}\left(C_{h, t}^{i}(j)\right)^{\frac{\mu-1}{\mu}}+\alpha_{i}^{\frac{1}{\mu}}\left(C_{f, t}^{i}(j)\right)^{\frac{\mu-1}{\mu}}\right]^{\frac{\mu}{\mu-1}},
$$

and the companion consumption price index $P_{t}^{i}$ is,

$$
P_{t}^{i}=\left[\left(1-\alpha_{i}\right)\left(P_{h, t}^{i}\right)^{1-\mu}+\alpha_{i}\left(P_{f, t}^{i}\right)^{1-\mu}\right]^{\frac{1}{1-\mu}},
$$

where $1-\alpha_{i} \in\left[0, \frac{1}{2}\right]$ is the home bias. The parameter $2 \alpha_{i}$ also proxies the openness of the final goods market in country $i$. Finally, $\mu \geq 1$ is the elasticity of substitution between domestic and foreign goods.

Consumption subindexes are,

$$
C_{h, t}^{i}(j)=\left[\int_{0}^{1} C_{h, t}^{i}(k, j)^{\frac{\theta-1}{\theta}} d k\right]^{\frac{\theta}{\theta-1}}, \text { and } C_{f, t}^{i}(j)=\left[\int_{0}^{1} C_{f, t}^{i}(k, j)^{\frac{\theta-1}{\theta}} d k\right]^{\frac{\theta}{\theta-1}} .
$$

$C_{h, t}^{i}(k, j)$ (resp. $\left.C_{f, t}^{i}(k, j)\right)$ is the consumption of a typical final good $k$ of home (resp. foreign) country by the representative consumer $j$ of country $i$ and $\theta>1$ is the elasticity of substitution between national varieties of final goods. We assume that firms do not discriminate the market they address and that their retail prices are identical in both countries. The corresponding prices of domestic and foreign goods in country $i$ are, $P_{h, t}^{i}=P_{h, t}=\left[\int_{0}^{1} P_{h, t}(k)^{1-\theta} d k\right]^{\frac{1}{1-\theta}}$ and $P_{f, t}^{i}=P_{f, t}=\left[\int_{0}^{1} P_{f, t}(k)^{1-\theta} d k\right]^{\frac{1}{1-\theta}}$, respectively. 
Accordingly, optimal variety demands are,

$$
\begin{aligned}
& C_{h, t}^{i}(k, j)=\left(1-\alpha_{i}\right)\left[\frac{P_{h, t}}{P_{t}^{i}}\right]^{-\mu}\left[\frac{P_{h, t}(k)}{P_{h, t}}\right]^{-\theta} C_{t}^{i}(j), \\
& C_{f, t}^{i}(k, j)=\alpha_{i}\left[\frac{P_{f, t}}{P_{t}^{i}}\right]^{-\mu}\left[\frac{P_{f, t}(k)}{P_{f, t}}\right]^{-\theta} C_{t}^{i}(j) .
\end{aligned}
$$

Since portfolio costs are paid in units of goods, i.e. $A C_{t}^{i}(j)=\left[\int_{0}^{1} A C_{t}^{i}(k, j)^{\frac{\theta-1}{\theta}} d k\right]^{\frac{\theta}{\theta-1}}$, they imply variety demands, defined as $A C_{t}^{i}(k, j)=\left[\frac{P_{h, t}(k)}{P_{h, t}}\right]^{-\theta} A C_{t}^{i}(j)$. Finally, we define the terms-of-trade in the currency area as,

$$
S_{t}=\frac{P_{f, t}}{P_{h, t}}
$$

\subsection{Firms}

Each firm produces a single variety $k$ in country $i \in\{h, f\}$ using national labor according to,

$$
Y_{t}^{i}(k)=A_{t}^{i} L_{t}^{i}(k), \text { with } A_{t+1}^{i}=\left(1-\rho_{a}\right) A^{i}+\rho_{a} A_{t}^{i}+\xi_{t+1}^{i},
$$

where $\xi_{t+1}^{i}$ is an i.i.d innovation with zero mean and constant variance.

Following Calvo [1983], we assume that in economy $i \in\{h, f\}$, a fraction $\left(1-\eta^{i}\right)$ of randomly selected firms is allowed to set new prices each period. Firms set prices higher in comparison of the typical mark-up pricing, depending on the expected period during which they will be unable to reset. The corresponding optimal price is,

$$
P_{i, t}^{*}(k)=\frac{\theta}{(\theta-1)(1-\tau)} \frac{\sum_{v=0}^{\infty}\left(\eta^{i} \beta\right)^{v} E_{t}\left\{\frac{Y_{t+\nu}^{i}(k)}{P_{t+\nu}^{i} C_{t+\nu}^{i}(j)^{\sigma}} W_{t}^{i} / A_{t}^{i}\right\}}{\sum_{v=0}^{\infty}\left(\eta^{i} \beta\right)^{v} E_{t}\left\{\frac{Y_{t+\nu}^{i}(k)}{P_{t+\nu}^{i} C_{t+\nu}^{i}(j)^{\sigma}}\right\}} .
$$

In this expression, $\tau$ is a subsidy that compensates the distorting effects of monopolistic competition in the economy. ${ }^{2} Y_{t}^{i}(k)$ is the aggregate demand addressed by firm $k$ on

2 Monopolistic competition distorts the first-best allocation through mark-up pricing and a lower output. An optimal subsidy policy restores the optimal perfectly competitive allocation. The importance of this result in the analysis of optimal monetary policy was brought to the attention of macroeconomists since Rotemberg and Woodford [1997] and discussed more recently by Benigno and Woodford [2005]. 
the final goods market. Aggregating among firms and assuming behavioral symmetry of Calvo producers, the average price of final goods in nation $i \in\{h, f\}$ is,

$$
P_{i, t}=\left[\left(1-\eta^{i}\right) P_{i, t}^{*}(k)^{1-\theta}+\eta^{i} P_{i, t-1}^{1-\theta}\right]^{\frac{1}{1-\theta}}
$$

\subsection{Governments}

Fiscal policy is aimed at closing first order distortions related to the monopolistic structure of final goods markets. ${ }^{3}$ Governments finance the corresponding subsidy made to firms through a lump-sum tax on households. Their budget constraint is,

$$
\int_{0}^{1} T_{t}^{i}(j) d j=-\tau \int_{0}^{1} P_{i, t}(k) Y_{t}^{i}(k) d k .
$$

\subsection{General equilibrium}

For any sequence of productivity shocks $\left\{A_{t}^{h}, A_{t}^{f}\right\}_{t=0}^{\infty}$, an equilibrium is a sequence of quantity $\left\{\mathcal{Q}_{t}\right\}_{t=0}^{\infty}$ where $Q_{t}=\left\{Y_{t}^{h}, Y_{t}^{f}, C_{t}^{h}, C_{t}^{f}, N_{t}^{h}, N_{t}^{f}, B_{t}^{h}, B_{t}^{f}, A C_{t}^{h}, A C_{t}^{f}\right\}_{t=0}^{\infty}$ that satisfies households and firms optimality conditions for a given set of prices $\left\{\mathcal{P}_{t}\right\}_{t=0}^{\infty}=$ $\left\{W_{t}^{h}, W_{t}^{f}, P_{t}^{h}, P_{t}^{f}, P_{h, t}, P_{f, t}^{f}, P_{h, t}^{*}(k), P_{f, t}^{*}(k)\right\}_{t=0}^{\infty}$ in a way that is compatible with the clearing of markets described below.

Defining aggregate supply bundles as $Y_{t}^{i}=\left[\int_{0}^{1} Y_{t}^{i}(k)^{\frac{\theta-1}{\theta}} d k\right]^{\frac{\theta}{\theta-1}}$ and assuming $\alpha_{h}=\alpha$ and $\alpha_{f}=1-\alpha$, final goods markets clear according to,

$$
\begin{aligned}
& Y_{t}^{h}=(1-\alpha)\left[\frac{P_{h, t}}{P_{t}^{h}}\right]^{-\mu} C_{t}^{h}+\alpha\left[\frac{P_{h, t}}{P_{t}^{f}}\right]^{-\mu} C_{t}^{f}+A C_{t}^{h}, \\
& Y_{t}^{f}=(1-\alpha)\left[\frac{P_{f, t}}{P_{t}^{f}}\right]^{-\mu} C_{t}^{f}+\alpha\left[\frac{P_{f, t}}{P_{t}^{h}}\right]^{-\mu} C_{t}^{h}+A C_{t}^{f} .
\end{aligned}
$$

Labor is immobile, so that $N_{t}^{i}=\int_{0}^{1} N_{t}^{i}(j) d j=\int_{0}^{1} L_{t}^{i}(k) d k$, and the aggregate production function of country $i \in\{h, f\}$ is $Y_{t}^{i} D P_{i, t}=A_{t}^{i} N_{t}^{i}$, where $D P_{i, t}=\int_{0}^{1}\left[\frac{P_{i, t}(k)}{P_{i, t}}\right]^{-\theta} d k$ is the dispersion of production prices in country $i$.

3 This assumption is crucial to eliminate the linear terms that arise in the second-order approximation of the utility function, insuring that our analysis is immune to the accuracy problem emphasized by Kim and Kim [2003]. 
The international financial market clearing condition is,

$$
\int_{0}^{1} B_{t}^{h}(j) d j+\int_{0}^{1} B_{t}^{f}(j) d j=0 .
$$

Finally, consolidating households, governments and firms resources constraints, the dynamics of net foreign assets in country $h$ is given by

$$
B_{t}^{h}-R_{t-1} B_{t-1}^{h}=P_{h, t} Y_{t}^{h}-P_{t}^{h} C_{t}^{h}
$$

\section{A linear-quadratic framework}

We solve the model applying standard linearization methods. We define the optimal policy as the minimization of a welfare loss function constrained by the model. This approach usually requires that the model is solved with a second order approximation to avoid spurious welfare reversals documented by Kim and Kim [2003]. However, Benigno and Woodford [2006] have shown that the solution of the optimal policy problem can be set in the convenient linear-quadratic form while remaining valid when the second order approximation of the welfare-based loss function yields a purely quadratic function, which is the case in our framework.

\subsection{Steady state}

The model is solved in log-deviation with respect to the symmetric steady state. In the symmetric steady state $A^{i}=A=1$ and $B^{i}=B=0$. Symmetry imposes $P_{h}=P_{f}=P^{h}$ $=P^{f}=P_{i}^{*}(k)=P$, implying, $\frac{W^{i}}{P^{i}}=\frac{W}{P}=\frac{(\theta-1)(1-\tau)}{\theta} A$. The compensation of first order distortions requires that the government sets $\tau=(1-\theta)^{-1} \leq 0$, implying $\frac{W}{P}=A$. Portfolio costs are zero so that $I=R=\beta^{-1}$. Price indexes are such that $D P=1$, final goods markets give $C=Y$, and the production function is $Y=A N$. Combining these

relations with the leisure arbitrage, we get, $Y=A^{\frac{1+\psi}{\psi+\sigma}}$. For tractability, we assume $A=1$, implying $Y=C=N=\frac{W}{P}=1$. Since the model features no money holding, the price level is defined arbitrarily to $P=1$.

\subsection{The model in deviation from the natural equilibrium}

The natural equilibrium, corresponding to the flexible price equilibrium with complete financial markets, is considered as the benchmark for the definition of the optimal policy. We thus express the linear dynamics of the model in deviation from the natural 
equilibrium. Applying the standard linearization procedure, we consider $x_{t}^{i}$ as the $\log -$ deviation of $X_{t}^{i}, \forall t$ for $i \in\{h, f\}$ from the steady state. Defining $\widetilde{x}_{t}$ as the natural equilibrium dynamics of $x_{t}$, we finally define the deviation of a variable from the natural equilibrium as $\widehat{x}_{t}=x_{t}-\widetilde{x}_{t}$.

\subsubsection{Complete financial markets}

Under complete financial markets, the model expressed in deviation from the natural equilibrium is given by,

$$
\begin{aligned}
\widehat{n}_{t}^{r} & =-\varpi_{\alpha} \widehat{s}_{t}, \\
\sigma E_{t}\left\{\widehat{c}_{t+1}^{u}\right\}-\sigma \widehat{c}_{t}^{u} & =\frac{\delta}{1+\delta} \widehat{r}_{t}-E_{t}\left\{\pi_{t+1}^{u}\right\}, \\
\sigma E_{t}\left\{\widehat{c}_{t+1}^{r}\right\}-\sigma \widehat{c}_{t}^{r} & =-(1-2 \alpha) E_{t}\left\{\pi_{t+1}^{r}\right\}, \\
\pi_{h, t} & =\beta E_{t}\left\{\pi_{h, t+1}\right\}+k^{h}\left[(\sigma+\psi) \widehat{c}_{t}^{u}-\psi \widehat{n}_{t}^{r}+\frac{1}{2} \widehat{s}_{t}\right], \\
\pi_{f, t} & =\beta E_{t}\left\{\pi_{f, t+1}\right\}+k^{f}\left[(\sigma+\psi) \widehat{c}_{t}^{u}+\psi \widehat{n}_{t}^{r}-\frac{1}{2} \widehat{s}_{t}\right], \\
\widehat{s}_{t}-\widehat{s}_{t-1} & =\pi_{f, t}-\pi_{h, t}+\frac{2(1+\psi)}{1+2 \psi \varpi_{\alpha}} a_{t}^{r}-\frac{2(1+\psi)}{1+2 \psi \varpi_{\alpha}} a_{t-1}^{r},
\end{aligned}
$$

where $\varpi_{\alpha}=\frac{(1-2 \alpha)^{2}+4 \sigma \mu \alpha(1-\alpha)}{2 \sigma}$ and $k^{i}=\frac{\left(1-\eta^{i} \beta\right)\left(1-\eta^{i}\right)}{\eta^{i}}$. In these expressions, $x^{u}=\frac{1}{2}\left(x^{h}+\right.$ $\left.x^{f}\right)$ is the average value of $X$ in the monetary union and $x^{r}=\frac{1}{2}\left(x^{f}-x^{h}\right)$ its relative value. Eq. (5) is the contraction of the relative expression of the final goods market equilibria (for the right-hand side element) and the relative production functions (for the left-hand side element). Eqs. (6) and (7) summarize the union-wide and relative expressions of Euler equations. Eqs. (8) and (9) are the expressions for modified Phillips curves, obtained by expressing marginal cost in terms of variables in deviation from the natural equilibrium.

\subsubsection{Incomplete financial markets}

We expose the dynamic equilibrium under incomplete financial markets. Since $B=0$, we define the $\log$-linear expression of $B_{t}^{i}$ as $b_{t}^{i}=\frac{B_{t}^{i} / C}{P_{t}^{i}}$. In this case, the model in deviation from the natural equilibrium, 


$$
\begin{aligned}
\widehat{n}_{t}^{r} & =(1-2 \alpha) \widehat{c}_{t}^{r}-2 \gamma \widehat{s}_{t}, \\
\sigma E_{t}\left\{\widehat{c}_{t+1}^{u}\right\}-\sigma \widehat{c}_{t}^{u} & =\frac{\delta}{1+\delta} \widehat{r}_{t}-E_{t}\left\{\pi_{t+1}^{u}\right\}, \\
\sigma E_{t}\left\{\widehat{c}_{t+1}^{r}\right\}-\sigma \widehat{c}_{t}^{r} & =\chi \widehat{b}_{t}^{h}-(1-2 \alpha) E_{t}\left\{\pi_{t+1}^{r}\right\}, \\
\pi_{h, t} & =\beta E_{t}\left\{\pi_{h, t+1}\right\}+k^{h}\left[(\sigma+\psi) \widehat{c}_{t}^{u}-\psi \widehat{n}_{t}^{r}-\sigma \widehat{c}_{t}^{r}+\alpha \widehat{s}_{t}\right], \\
\pi_{f, t} & =\beta E_{t}\left\{\pi_{f, t+1}\right\}+k^{f}\left[(\sigma+\psi) \widehat{c}_{t}^{u}+\psi \widehat{n}_{t}^{r}+\sigma \widehat{c}_{t}^{r}-\alpha \widehat{s}_{t}\right], \\
\widehat{s}_{t}-\widehat{s}_{t-1} & =\pi_{f, t}-\pi_{h, t}+\frac{2(1+\psi)}{1+2 \psi \varpi_{\alpha}} a_{t}^{r}-\frac{2(1+\psi)}{1+2 \psi \varpi_{\alpha}} a_{t-1}^{r}, \\
\widehat{b}_{t}^{h}-\beta^{-1} \widehat{b}_{t-1}^{h} & =\alpha[2 \mu(1-\alpha)-1] \widehat{s}_{t}+2 \alpha \widehat{c}_{t}^{r},
\end{aligned}
$$

where $\gamma=\mu \alpha(1-\alpha)$.

The equations are slightly modified with respect to the case of complete financial markets. Since the risk-sharing condition does not hold anymore, Eq.(11) indicates that the equilibrium of the final goods markets depends both on relative consumption and on the terms-of-trade. Eq.(12) is unchanged. Eq.(13) is the contraction of Euler equations and shows that the risk-sharing condition is broken, since $\chi \widehat{b}_{t}^{h}$ is the gap between relative consumptions and the terms-of-trade. Using the current account $\widehat{b}_{t}^{h}-\widehat{b}_{t-1}^{h}$ to adjust externally clearly increases the distance from perfect international risk-sharing. Eqs. (14) and (15) are the expressions for modified Phillips curves when relative consumptions and the terms-of-trade are not tied by the risk-sharing condition. Eq.(16) is unchanged. Finally, Eq.(17) describes the dynamics of net foreign assets where $\alpha[2 \mu(1-\alpha)-1] \widehat{s}_{t}+2 \alpha \widehat{c}_{t}^{r}$ is the trade balance at time $t$.

\subsection{The authorities loss function}

To determine the optimal policy and to rank alternative situations, we adopt a welfare measure based on the aggregate utility function,

$$
\omega_{T}=\frac{1}{2} \int_{0}^{1} \omega_{T}^{h}(j) d j+\frac{1}{2} \int_{0}^{1} \omega_{T}^{f}(j) d j
$$

where, after using symmetry among agents,

$$
\omega_{T}^{i}(j)=\omega_{T}^{i}=E_{0} \sum_{t=0}^{T} \beta^{t}\left\{\frac{\left(C_{t}^{i}\right)^{1-\sigma}}{(1-\sigma)}-\frac{\left(N_{t}^{i}\right)^{1+\psi}}{(1+\psi)}\right\} .
$$

The welfare measure is computed using second-order approximations of $\omega_{T}$ and equilibrium conditions, and expressed as a quadratic function of endogenous variables in deviation from their natural equilibrium paths, ${ }^{4}$

$\overline{4}$ The extensive derivation is available in appendix. 


$$
\omega_{T}=-\frac{1}{2} E_{0} \sum_{t=0}^{T} \beta^{t}\left\{\frac{\theta}{2 k^{h}} \pi_{h, t}^{2}+\frac{\theta}{2 k^{f}} \pi_{f, t}^{2}+(\sigma+\psi)\left(\widehat{c}_{t}^{u}\right)^{2}+\gamma\left(\widehat{s}_{t}\right)^{2}+\sigma\left(\widehat{c}_{t}^{r}\right)^{2}+\psi\left(\widehat{n}_{t}^{r}\right)^{2}\right\} .
$$

The welfare measure (18) admits standard arguments, such as national inflation rates and the aggregate consumption gap. However, the welfare measure also penalizes regional asymmetries, since deviations of terms-of-trade, of relative consumption and of relative effort are costly.

\section{Monetary policy}

In this section, we compute the optimal monetary policy under complete and incomplete financial markets, and then consider that the common Central Bank follows an interest rate rule that in fact may not be optimal.

\subsection{Optimal policy under complete and incomplete financial markets}

We first compute the optimal plan under complete financial markets. It is defined as the minimization of the welfare loss function (18) subject to the linear dynamic system (5)-(10). Assuming that the social planner can commit for an infinity of periods and adopting Woodford's timeless perspective, the optimal policy is obtained by minimizing the following Lagrangian,

$$
\begin{aligned}
\mathcal{L}_{\text {complete }} & =E_{0} \sum_{t=0}^{T} \beta^{t}\left\{\frac{\theta}{2 k^{h}} \pi_{h, t}^{2}+\frac{\theta}{2 k^{f}} \pi_{f, t}^{2}+(\sigma+\psi)\left(\widehat{c}_{t}^{u}\right)^{2}+\frac{\varpi_{\alpha}}{2} \widehat{s}_{t}^{2}+\psi\left(\widehat{n}_{t}^{r}\right)^{2}\right. \\
& +2 \Lambda_{1, t}\left[\pi_{h, t}-\beta E_{t}\left\{\pi_{h, t+1}\right\}-k^{h}\left((\sigma+\psi) \widehat{c}_{t}^{u}-\psi \widehat{n}_{t}^{r}+\frac{1}{2} \widehat{s}_{t}\right)\right] \\
& +2 \Lambda_{2, t}\left[\pi_{f, t}-\beta E_{t}\left\{\pi_{f, t+1}\right\}-k^{f}\left((\sigma+\psi) \widehat{c}_{t}^{u}+\psi \widehat{n}_{t}^{r}-\frac{1}{2} \widehat{s}_{t}\right)\right] \\
& \left.+2 \Lambda_{3, t}\left[\widehat{s}_{t}-\widehat{s}_{t-1}-\pi_{f, t}+\pi_{h, t}-\frac{2(1+\psi)}{1+2 \psi \varpi_{\alpha}} a_{t}^{r}+\frac{2(1+\psi)}{1+2 \psi \varpi_{\alpha}} a_{t-1}^{r}\right]\right\} .
\end{aligned}
$$

After some algebra, first order conditions collapse to the following optimal targeting 
rules,

$$
\begin{aligned}
\frac{\theta}{2}\left(\pi_{h, t}+\pi_{f, t}\right) & =-\left(\widehat{c}_{t}^{u}-\widehat{c}_{t-1}^{u}\right)-\Lambda_{3, t}\left(k^{h}-k^{f}\right), \\
\frac{\theta}{2}\left(\pi_{f, t}-\pi_{h, t}\right) & =-\left(\widehat{n}_{t}^{r}-\widehat{n}_{t-1}^{r}\right)+\Lambda_{3, t}\left(k^{h}+k^{f}\right), \\
\Lambda_{3, t-1}-\beta \Lambda_{3, t} & =-\varpi_{\alpha} \widehat{s}_{t-1}-\alpha \widehat{n}_{t-1}^{r}, \\
\widehat{c}_{t}^{r} & =-\frac{(1-2 \alpha)}{2 \sigma} \widehat{s}_{t},
\end{aligned}
$$

augmented with constraints (8)-(10).

Second, we compute the optimal plan under financial market incompleteness. The optimal policy is obtained by minimizing the following Lagrangian,

$$
\begin{aligned}
\mathcal{L}_{\text {incomplete }} & =E_{0} \sum_{t=0}^{T} \beta^{t}\left\{\frac{\theta}{2 k^{h}} \pi_{h, t}^{2}+\frac{\theta}{2 k^{f}} \pi_{f, t}^{2}+(\sigma+\psi)\left(\widehat{c}_{t}^{u}\right)^{2}+\gamma\left(\widehat{s}_{t}\right)^{2}+\sigma\left(\widehat{c}_{t}^{r}\right)^{2}+\psi\left(\widehat{n}_{t}^{r}\right)^{2}\right. \\
& +2 \Lambda_{1, t}\left[\pi_{h, t}-\beta E_{t}\left\{\pi_{h, t+1}\right\}-k^{h}\left((\sigma+\psi) \widehat{c}_{t}^{u}-\psi \widehat{n}_{t}^{r}-\sigma \widehat{c}_{t}^{r}+\alpha \widehat{s}_{t}\right)\right] \\
& +2 \Lambda_{2, t}\left[\pi_{f, t}-\beta E_{t}\left\{\pi_{f, t+1}\right\}-k^{f}\left((\sigma+\psi) \widehat{c}_{t}^{u}+\psi \widehat{n}_{t}^{r}+\sigma \widehat{c}_{t}^{r}-\alpha \widehat{s}_{t}\right)\right] \\
& \left.+2 \Lambda_{3, t}\left[\widehat{s}_{t}-\widehat{s}_{t-1}-\pi_{f, t}+\pi_{h, t}-\frac{2(1+\psi)}{1+2 \psi \varpi_{\alpha}} a_{t}^{r}+\frac{2(1+\psi)}{1+2 \psi \varpi_{\alpha}} a_{t-1}^{r}\right]\right\} .
\end{aligned}
$$

After some algebra, first order conditions collapse to the following optimal targeting rules,

$$
\begin{aligned}
\widehat{c}_{t}^{r} & =\widehat{n}_{t}^{r}, \\
\frac{\theta}{2}\left(\pi_{h, t}+\pi_{f, t}\right) & =-\left(\widehat{c}_{t}^{u}-\widehat{c}_{t-1}^{u}\right)-\Lambda_{3, t}\left(k^{h}-k^{f}\right), \\
\frac{\theta}{2}\left(\pi_{f, t}-\pi_{h, t}\right) & =-\left(\widehat{n}_{t}^{r}-\widehat{n}_{t-1}^{r}\right)+\Lambda_{3, t}\left(k^{h}+k^{f}\right), \\
\Lambda_{3, t-1}-\beta \Lambda_{3, t} & =-\gamma \widehat{s}_{t-1}-\alpha \widehat{n}_{t-1}^{r}, \\
\widehat{c}_{t}^{r} & =-\frac{(1-2 \alpha)}{2 \sigma} \widehat{s}_{t},
\end{aligned}
$$

augmented with constraints (14)-(16).

\subsection{Interest rate rule}

We assume that the common Central Bank commits to a price stability policy. A full stabilization of the aggregate inflation rates and output gap implies $\pi_{t}^{u}=\widehat{c}_{t}^{u}=0, \forall t$. 
However, $\widehat{r}_{t}=0$ or equivalently $r_{t}=\widetilde{r}_{t}$ can not be interpreted as a rule that the Central Bank could follow to implement its price stability policy.

As shown by Gali and Monacelli [2005], setting $\widehat{r}_{t}=0$ results in indeterminacy. Uniqueness can be restored by having the Central Bank committing to the following rule,

$$
\widehat{r}_{t}=\phi_{\pi} \pi_{t}^{u}
$$

or equivalently,

$$
r_{t}=\widetilde{r}_{t}+\phi_{\pi} \pi_{t}^{u}
$$

This policy rule will be referred to as an optimal Taylor-type monetary policy rule (or IRR1), since this policy rule permits the implementation of the optimal monetary policy consisting in aggregate price stability. However, it is often argued that monetary authorities could not commit to such a rule because the natural real interest rate (depending on models underlying shocks) is not observable. For this reason, we also investigate the case where the common Central Bank commits itself to the following rule,

$$
r_{t}=\phi_{\pi} \pi_{t}^{u}
$$

referred to as a simple Taylor-type rule (or IRR2).

\section{Dynamics}

In this section, we calibrate the model under both complete and incomplete financial markets. We then analyze the dynamic properties in both cases and highlight the mechanisms behind our results.

\subsection{Baseline parameterization}

We calibrate the deep parameters of the model based on standard values found in the literature. Following Beetsma and Jensen [2005], the degree of risk aversion is $\sigma=2$. The value of $\psi$ refers to Canzoneri, Cumby and Diba [2007] and varies between 5 and 15. For the baseline case, we choose $\psi=5$. In the literature, estimates of $\mu$, the elasticity of substitution between domestic and foreign goods, range from 1 to 12. For example, estimates of Backus, Kehoe and Kydland [1995] range from 1 to 2 while estimates of Harrigan [1993] range from 5 to 12 . We set $\mu=2$ and then check for robustness with other values of this parameter (from 1 to 10). The elasticity of substitution across varieties determines the average mark-up, which according to Rotemberg and Woodford [1997] is around 16-17\%, implying $\theta=7$. We set the openness parameter to $\alpha=0.25$ in the benchmark calibration and, following Faia [2007], we let it vary from 0.25 to 0.4 . The parameter controlling nominal rigidities 
ranges, according to different estimates, from 0.5 to 0.8. Following Canzoneri et al. [2007], we set the baseline value at $\eta^{h}=\eta^{f}=0.75$. The portfolio cost parameter $\chi$ is set to 0.001 , corresponding to an average annual interest rate premium of $0.405 \%$, in line with Schmitt-Grohe and Uribe [2003] and Benigno [2007]. Other parameters are fairly standard: $\beta=0.988, \rho_{a}=0.95$ and $s t d\left(\xi_{t}^{i}\right)=0.7 \%$. Finally, the reaction coefficient in the monetary policy rules is $\phi_{\pi}=1.5$.

\subsection{Dynamics with optimal monetary policy}

In the case of complete financial markets, the risk-sharing condition holds implying that external adjustment after asymmetric shocks hinge on real exchange rate fluctuations only, namely,

$$
\widehat{c}_{t}^{r}=-\frac{(1-2 \alpha)}{2 \sigma} \widehat{s}_{t}
$$

The basic intuition of the paper is that the incompleteness of financial markets may improve the welfare in a second-best environment. The Central Bank of the monetary union, reacting to union wide of the inflation rate when asymmetric shocks arise, is not able to stabilize fluctuations of national inflation rates. As a consequence, the way the external equilibrium is reached under alternative structures has an impact on the volatility of the terms-of-trade, and thus on national inflation rates which entails significant welfare consequences. In particular, our main result is that the incompleteness of financial markets promotes a smoother ride of terms-of-trade, and thus of countrylevel inflation rates, which is the most heavily weighted component of the welfare measure (Eq. 18). Despite the losses implied by imperfect risk-sharing among currency area participants, we show that the welfare improving effect of financial markets incompleteness dominates.

Figure 1 plots the Impulse Response Functions (IRFs) of interest variables in the monetary union after a unit domestic productivity innovation when the Central Bank targets an optimal monetary policy both in the case of complete and incomplete financial markets. The figure illustrates the smoothing effect that financial markets incompleteness exerts on national inflation rates in the case of an asymmetric productivity shock.

A positive productivity shock reduces the marginal cost of domestic firms, and thus implies a significant deflation. The optimal policy requires that policymakers make use of their monetary instruments, for example the nominal interest rate, to stabilize the aggregate inflation. This policy requires that the foreign economy experiences a significant level of inflation that exactly offsets the domestic deflation and implies a zero aggregate inflation rate in the equilibrium. Moreover, since prices are sticky, termsof-trade are also sticky and a negative terms-of-trade gap thus arises: terms-of-trade increase in the natural equilibrium with flexible prices and complete markets, but not as much in the sticky-price environment. 
Fig. 1. Impulse response functions to a unit domestic productivity innovation with optimal monetary policy, in \% deviations from natural equilibrium.
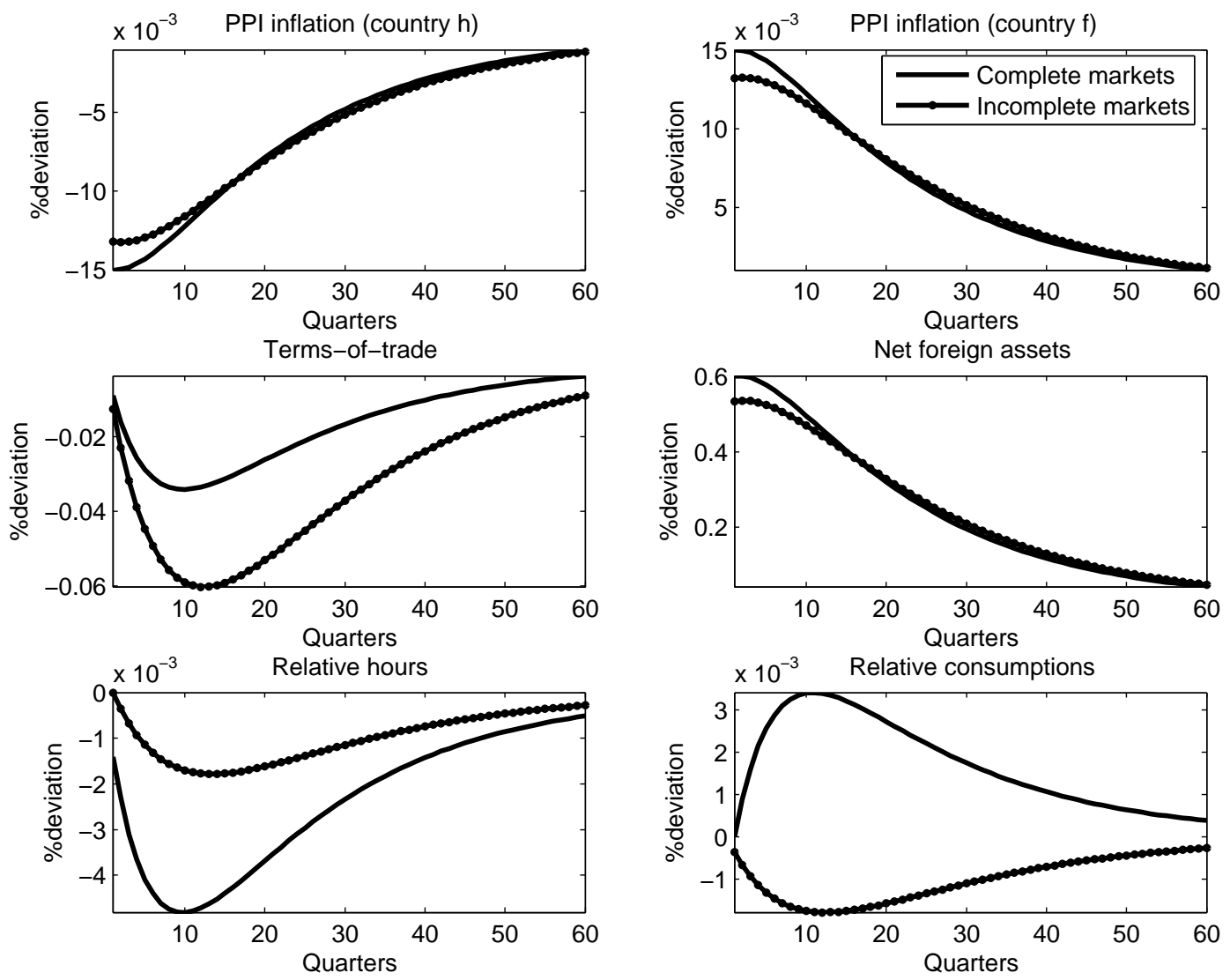

Under complete financial markets, the external adjustment of currency area members when undergoing asymmetric productivity shocks relies exclusively on the real exchange rate (that exactly corresponds to the terms-of-trade in our setting) and assets quantities do not change. As a consequence, the risk-sharing condition induces a positive gap of relative private consumptions, while the standard wealth effect would give rise to a negative gap of relative private consumption (an over-adjustment of the domestic consumption triggered by the deflation and an under-adjustment of the foreign consumption triggered by the inflation).

Under incomplete financial markets, the pressure on the terms-of-trade to adjust externally is lower. The external adjustment of currency area members occurs through the additional channel of assets quantities. As a consequence, the gap of the termsof-trade and the gap of the relative consumptions are thus determined independently that results in lower cumulated responses of national inflation rates and increases the response of the gap of the terms-of-trade. Indeed, since the terms-of-trade are less responsive, their distance to the natural equilibrium increases when national inflation rate become less responsive. Since the negative relation between the gap of the termsof-trade and the gap of the relative consumptions is broken, the wealth effect now entirely drives a negative relative consumption gap. 


\subsection{Dynamics with interest rate rule}

We now study the dynamics of the economy assuming that the Central Bank follows an interest rate rule as described in Section 4.2.

Fig. 2. Impulse response functions to a unit domestic productivity innovation with interest rate rule, in \% deviations from natural equilibrium.
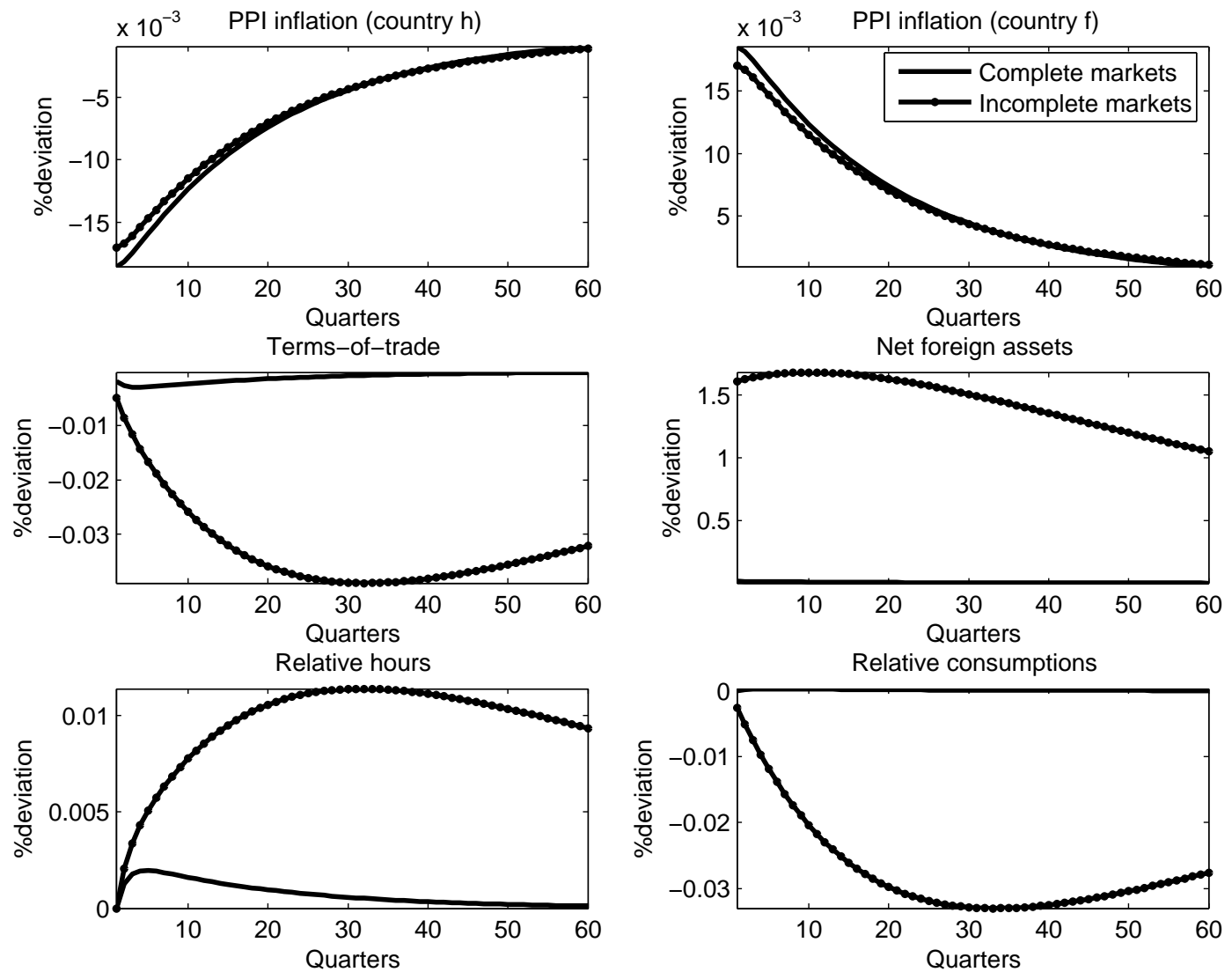

One may remark by looking at Figure 2 that the adjustment pattern of the countrylevel inflation rates and of the gap of terms-of-trade is unchanged. The productivity shock implies a deflation in the domestic economy and a positive response of inflation in the foreign economy, triggered by the Central Bank's reaction that lowers its nominal interest rate and increases the transmission of the shocks among the currency area members. Terms-of-trade thus increase but not as much as under flexible prices and a negative terms-of-trade gap arises.

Under complete financial markets, the reaction of the terms-of-trade is higher (the gap is lower) because the external adjustment relies only on the terms-of-trade, which drives-up the reaction of the country-level inflation rates after the shock. Risk-sharing is better however in this case and the distance to the natural equilibrium is much lower under complete financial markets, as depicted by the small magnitude of the responses 
of the gaps of relative hours, of the relative consumptions and of the net foreign assets. The risk-sharing condition implies a positive gap of relative private consumptions. In addition, the gap of relative hours - that is strictly equivalent to the gap of relative output levels - is positive. The output gap is negative in the domestic economy and positive in the foreign economy, which is consistent with the reaction of country-level inflation rates.

Under incomplete financial markets, the reaction of the terms-of-trade is lower (the gap is higher) because the external adjustment now relies both on the terms-of-trade and on the current account, which tends to smooth the reaction of the country-level inflation rates after the shock and enhance the reaction of the relative hours, the relative consumptions and the net foreign assets. In this case, much of the external adjustment and of the smoothing of relative wealth across countries and time occurs through the measure of the current account that captures changes in assets quantities. Consequently, the adjustment to transitory shocks in this environment is driven more by changes in quantities (consumptions, hours) while the adjustment under complete financial markets is driven more by changes in prices. For that reason, the persistence of the shocks is playing a key role in terms of the quantitative differences between incomplete and complete financial markets, as the equilibrium under both specifications tends to rely more on prices as shocks become more permanent.

\section{Welfare costs/gains}

In this section, we measure the welfare costs or gains arising under alternative financial structures in a monetary union subject to asymmetric productivity shocks. We do this for different monetary policy specifications. We highlight the fact that financial markets incompleteness yields welfare gains that more than compensate the welfare costs related to imperfect risk-sharing as long as $(i)$ prices are sticky enough and $(i i)$ private consumption is home biased. These results hold under all specifications of the monetary policy (optimal plan, a Taylor-type rule and a simple Taylor-type rule) and for most plausible values of parameters.

One may notice that if the result holds for any degree of price stickiness under the optimal plan, it holds under a Taylor-type rule as long as the degree of price stickiness lies above a certain threshold $(\eta=0.38)$. In these cases, financial markets incompleteness is associated with a lower volatility of national inflation rates since the external adjustment after asymmetric productivity shocks relies less on the terms-of-trade as revealed by the analysis of IRFs. In addition, we show that the sharing of the risk allowed by complete markets is welfare improving when prices are flexible. Finally, openness on goods markets dramatically reduces the welfare distance between incomplete and complete financial markets equilibriums, as demonstrated by Cole and Obstfeld [1991]. Finally, we check the robustness of our results to variations of the deep parameters and 
conclude the section by allowing the degree of price rigidity to differ across countries.

Welfare gains/losses are expressed in terms of permanent consumption, so that,

$$
\Omega_{T}^{a, b}=\left(\frac{1-\beta}{\sigma+\psi}\left(\omega_{T}^{a}-\omega_{T}^{b}\right)\right)^{\frac{1}{2}}
$$

where $\omega_{T}^{a}$ and $\omega_{T}^{b}$ are the welfare in two different monetary policy situations for the same financial market structure or two different situations in terms of financial market structure for the same monetary policy regime.

\subsection{Price stickiness and welfare}

Welfare gains/losses of risk sharing of alternative financial structures and monetary policies are reported in Table 1.

Table 1

Welfare analysis.

\begin{tabular}{|c|c|c|c|c|c|c|}
\hline & \multicolumn{2}{|c|}{$\Omega^{o p t, r u l e}$} & \multicolumn{4}{|c|}{$\Omega^{\text {complete,incomplete }}$} \\
\hline & Complete & Incomplete & Flexible prices* & Optimal plan & IRR 1 & IRR 2 \\
\hline Baseline & 0.0226 & 0.0218 & 0.0052 & -0.0166 & -0.0176 & -0.0192 \\
\hline$\psi=10$ & 0.0174 & 0.0174 & 0.0037 & -0.0120 & -0.0121 & -0.0136 \\
\hline$\psi=15$ & 0.0147 & 0.0149 & 0.0030 & -0.0099 & -0.0097 & -0.0111 \\
\hline$\sigma=1$ & 0.0224 & 0.0196 & 0.0061 & -0.0174 & -0.0205 & -0.0211 \\
\hline$\sigma=5$ & 0.0199 & 0.0204 & 0.0037 & -0.0141 & -0.0134 & -0.0172 \\
\hline$\alpha=0.35$ & 0.0192 & 0.0214 & 0.0028 & -0.0139 & -0.0101 & -0.0126 \\
\hline$\alpha=0.4$ & 0.0183 & 0.0213 & 0.0018 & -0.0132 & -0.0073 & -0.0105 \\
\hline$\mu=1$ & 0.0439 & 0.0358 & 0.0086 & -0.0304 & -0.0396 & -0.0403 \\
\hline$\mu=5$ & 0.0079 & 0.0088 & 0.0023 & -0.0064 & -0.0050 & -0.0090 \\
\hline$\mu=10$ & 0.0033 & 0.0040 & 0.0012 & -0.0028 & -0.0016 & -0.0077 \\
\hline$\eta=0.7$ & 0.0163 & 0.0152 & - & -0.0127 & -0.0140 & -0.0153 \\
\hline$\eta=0.8$ & 0.0324 & 0.0319 & - & -0.0219 & -0.0227 & -0.0246 \\
\hline$\rho_{a}=0.9$ & 0.0523 & 0.0511 & 0.0105 & -0.0338 & -0.0357 & -0.0391 \\
\hline$\rho_{a}=0.99$ & 0.0031 & 0.0025 & 0.0008 & -0.0026 & -0.0031 & -0.0032 \\
\hline
\end{tabular}

${ }^{*} \eta=0.0001$. Note: a negative sign signals welfare losses. 
Consistent with other studies (see Kim, Kim and Levin [2003]), when prices are flexible, we find that incomplete financial markets imply imperfect risk-sharing, generating welfare losses rising to an average decrease of permanent consumption of about $0.0052 \%$ (third column of Table 1). Alternatively, interpreting the situation of flexible prices as a situation where independent national monetary policies stabilize national inflation rates, our results are directly related to those of Benigno [2007]. We report results of the same magnitude since risk-sharing is associated to an average $0.0052 \%$ welfare gain while he reports gains ranging from $0.0024 \%$ for $\sigma=1$ to $0.0069 \%$ for $\sigma=6$ with productivity shocks only. Our results also comfort those of Cole and Obstfeld [1991] according to which trade integration may help replicating the complete asset markets equilibrium. Indeed, openness clearly lowers the magnitude of welfare gains related to risk-sharing (see also Figure 3).

When prices are sticky, Tables 1 and 2 provide a set of results indicating that (i) the optimal plan always Pareto-dominates the equilibrium with a Taylor-type monetary policy rule and (ii) incomplete financial markets prove welfare enhancing for most plausible values of the deep parameters both under the optimal plan and under monetary policy rules.

Detailing the first set of results, the first and second columns of Table 1 indicate that commitment to the optimal plan yields welfare gains with respect to Taylor-type rules reaching $0.0226 \%$ and $0.0218 \%$ respectively under complete and incomplete financial markets. More generally, Table 1 displays welfare gains of following the Ramsey policy ranging from $0.0033 \%$ to $0.0523 \%$. These figures are in clear accordance with those of Gali and Monacelli [2005] and those of Benigno [2007]. As policy become more and more distant from the optimal plan, Table 2 displays increasing volatilities of country-level inflation rates both under complete and incomplete financial markets. Finally, one shall notice that the volatility of the aggregate consumption gap is zero both under the optimal plan and the first type of Taylor rule while it is positive when the central bank commits to a simple Taylor-type rule. In this last case, when the currency area experiences asymmetric shocks, the aggregate inflation rate is not fully stabilized and as a consequence, country-level inflation rates do not fluctuate by the same magnitude (while they still move in opposite directions as under the optimal plan and under optimal Taylor-type rules). This remark is important because it indicates that results concerning the welfare gains of incomplete financial markets are robust to the specification of monetary policy rules.

We now analyze the results displayed by columns 4, 5 and 6 of Table 1 , showing that incomplete financial markets are associated to welfare gains with respect to the situation of perfect risk-sharing. As demonstrated by the analysis of the impulse response functions after an asymmetric home productivity shock, incomplete financial markets introduce an additional external adjustment channel and restore the role of the current account. The general idea behind our results is thus that incomplete financial markets, by allowing the external adjustment to rely on the current account and lowering the 
pressure on terms-of-trade, give rise to less volatile country-level inflation rates, as depicted in Table 2. In the loss function and for the baseline calibration, weights on inflation are $\frac{\theta}{2 k} \simeq 40$ while weights on terms-of-trade gaps, relative consumptions gaps and relative hours gaps are respectively $\mu \alpha(1-\alpha) \simeq 0.37, \sigma=2$ and $\psi=5$. As a consequence, welfare gains associated with lower volatility of inflation rates more than compensate for welfare losses related to higher volatility of gaps in terms-of-trade, relative consumptions or relative hours (see Table 2). The situation of incomplete financial markets thus Pareto-dominates the situation of complete financial markets in a monetary union characterized by sticky prices and subject to asymmetric productivity shocks. According to our results displayed in Table 1, the incompleteness of financial markets is associated to an average $0.0166 \%$ welfare gain under the optimal plan, $0.0176 \%$ when monetary policy is conducted using an optimal Taylor-type rule and $0.0192 \%$ when monetary policy is being conducted using a simple Taylor-type rule.

Table 2

Standard deviations for the baseline calibration, in \%.

\begin{tabular}{|c|c|c|c|c|c|c|}
\hline & $\operatorname{std}\left(\pi_{h, t}\right)$ & $\operatorname{std}\left(\pi_{f, t}\right)$ & $\operatorname{std}\left(\widehat{c}_{t}^{u}\right)$ & $\operatorname{std}\left(\widehat{s}_{t}\right)$ & $\operatorname{std}\left(\widehat{c}_{t}^{r}\right)$ & $\operatorname{std}\left(\widehat{n}_{t}^{r}\right)$ \\
\hline \multicolumn{7}{|l|}{ Flexible prices* } \\
\hline Complete markets & - & - & - & - & - & - \\
\hline Incomplete markets & - & - & - & 0.014 & 0.012 & 0.004 \\
\hline \multicolumn{7}{|l|}{ Sticky prices - optimal plan } \\
\hline Complete markets & 0.017 & 0.017 & 0.000 & 0.024 & 0.0003 & 0.003 \\
\hline Incomplete markets & 0.015 & 0.015 & 0.000 & 0.037 & 0.000 & 0.000 \\
\hline \multicolumn{7}{|l|}{ Sticky prices - IRR 1} \\
\hline Complete markets & 0.020 & 0.020 & 0.000 & 0.002 & 0.000 & 0.002 \\
\hline Incomplete markets & 0.018 & 0.018 & 0.000 & 0.015 & 0.112 & 0.005 \\
\hline \multicolumn{7}{|l|}{ Sticky prices - IRR 2} \\
\hline Complete markets & 0.023 & 0.023 & 0.001 & 0.002 & 0.000 & 0.002 \\
\hline Incomplete markets & 0.021 & 0.021 & 0.001 & 0.015 & 0.012 & 0.005 \\
\hline
\end{tabular}

$* \eta=0.0001$.

\subsection{Sensitivity analysis}

Figure 3, 4 and 5 complement the results described in Table 1 and 2 by running a more systematic sensitivity analysis of our main results. The general conclusion of this sensitivity analysis is twofold. First, key parameters in generating our results are the preferences parameters (the elasticity of labor supply, the risk-aversion parameter, 
home bias), the parameters determining the degree of prices stickiness and those governing the persistence of the exogenous shocks. Second, alternative specifications for the common monetary policy have marginal effects on the magnitude of the results, implying that the relevant assumption is the existence of a currency area with a central bank targeting the aggregate inflation rate.

Fig. 3. Welfare gains for different levels of openness $(\alpha)$, of nominal rigidities $(\eta)$, of financial market incompleteness $(\chi)$ and of the persistence of the shock $\left(\rho_{a}\right)$ under optimal policy rule.
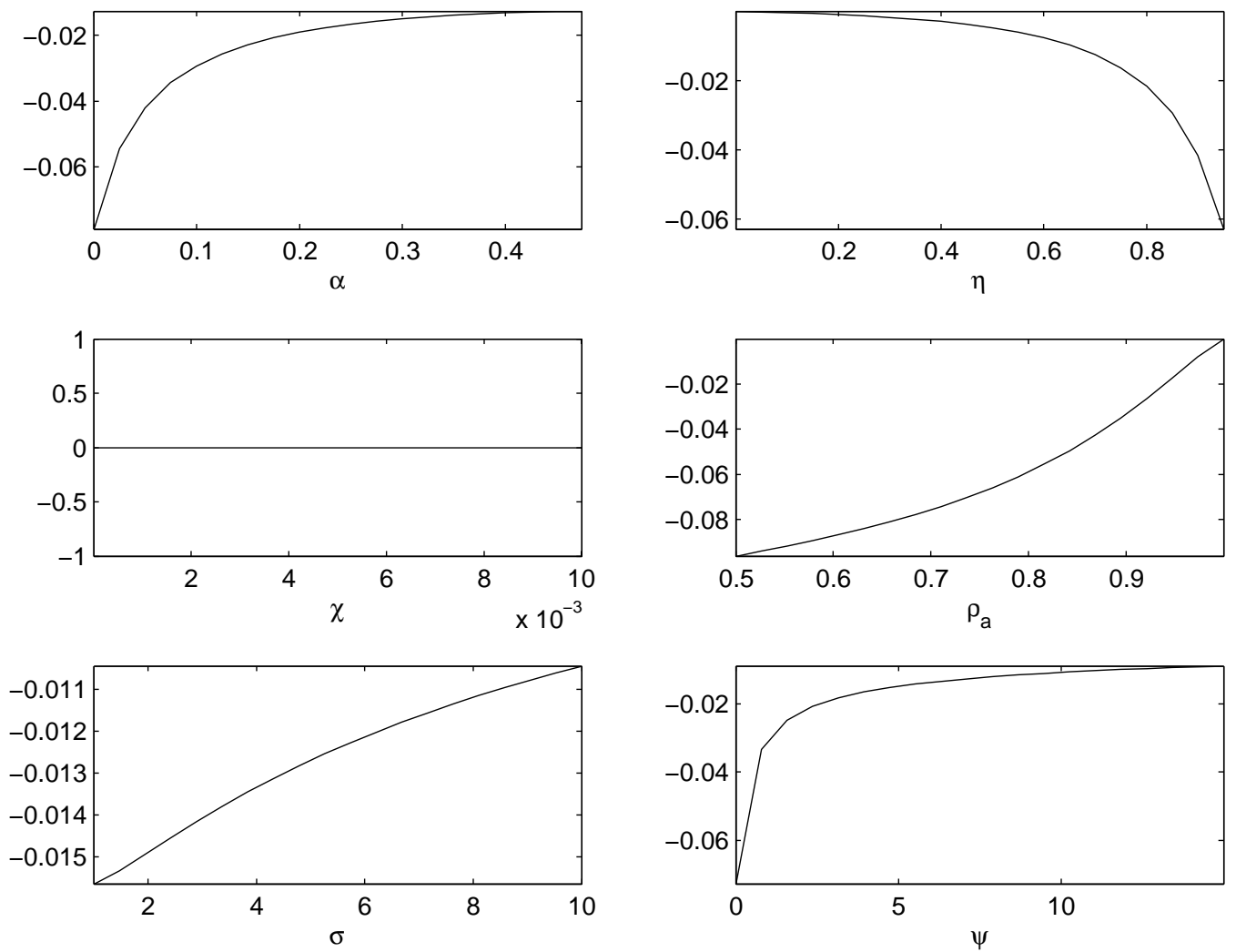

The sensitivity results may be summarized as follows:

(i): The Frischian elasticity $\psi$ lowers the welfare losses independently of the financial structure, since fluctuations have less impact on hours worked.

(ii): First, the risk-aversion parameter $\sigma$ also lowers the volatility of private consumptions, which lowers the overall costs of economic fluctuations. Second, risk-aversion crucially affects the volatility of the terms-of-trade, at the heart of our results. Under complete financial markets, the risk-sharing condition is binding, implying that higher values of $\sigma$ lower the volatility of the terms-of-trade required to adjust externally for a given volatility of relative consumptions. As a result, the volatility of country-level inflation rates under complete financial markets is reduced by an increase of $\sigma$ and the welfare distance between complete and incomplete situations is dampened.

(iii): $\alpha$ exerts powerful effects on our results. On one hand, $\alpha$ increases the volume of 
Fig. 4. Welfare gains for different levels of openness $(\alpha)$, of nominal rigidities $(\eta)$, of financial market incompleteness $(\chi)$ and of the persistence of the shock $\left(\rho_{a}\right)$ under interest rate rule.
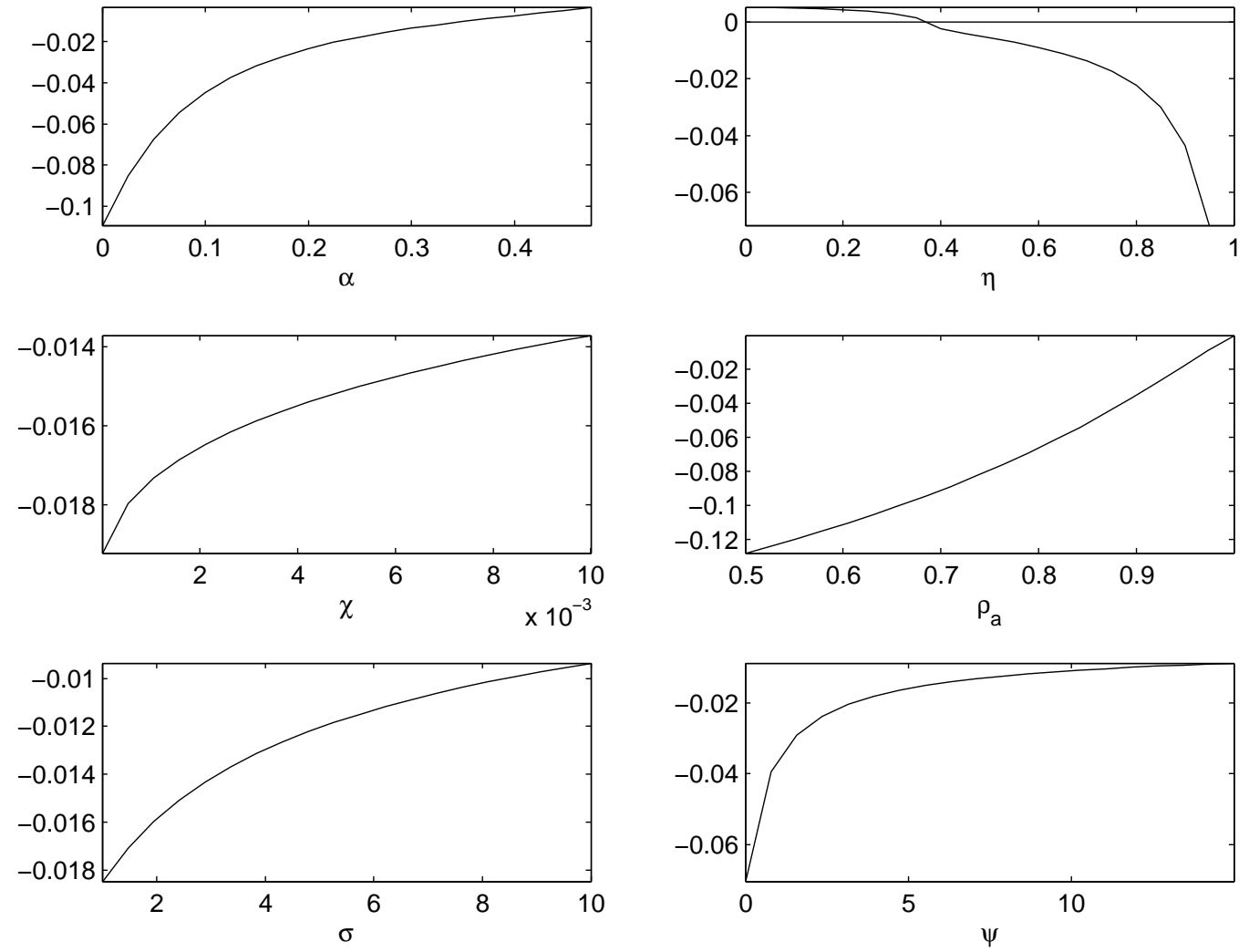

goods traded and implies a higher volatility of the current account. Since the current account is at the heart of our results, an increase of $\alpha$ should amplify welfare gains associated with incomplete financial markets. On the other hand, the risk-sharing condition shows that a higher value of $\alpha$ implies a lower response in the terms-of-trade to a given variation of relative consumptions. The implied lower terms-of-trade is welfare enhancing and, again, dominates the first effect.

(iv): The elasticity of substitution between home and foreign goods, $\mu$, impacts negatively the welfare gains associated with incomplete financial markets. When goods become better substitutes, (i) the expenditure-switching effect is higher for a given variation of relative prices, i.e. the terms-of-trade, or (ii) the required variation of the terms-of-trade to meet the external equilibrium is lower. In both cases, the welfare distance between complete and incomplete financial markets determined by differences in terms of terms-of-trade volatilities, tend to decrease.

$(v)$ : The degree of price stickiness has a positive impact on welfare gains associated with incomplete financial markets. When differences in country-level inflation rates become more persistent, a mechanism that lowers cumulated country-level inflation rates becomes more and more attractive from a normative point of view, i.e. in terms of welfare. Moreover, higher values of $\eta$ are associated with lower $k^{i}$ and improve the weight of national PPI inflation rates in the welfare function. 
Running simulations across the whole spectrum of possible values of $\eta$ in the case of symmetric nominal rigidities, Figure 4 highlights the fact that when prices become more flexible, there is a point at which financial markets incompleteness becomes costly in terms of welfare. For the baseline calibration of the model, the threshold value corresponds to $\eta=0.38$. As long as $\eta$ is inferior to this threshold value, the costs of imperfect risk-sharing dominate the gains of smoother national inflation rates.

(vi): Figure 3 and 4 also report the welfare gains of financial markets incompleteness for varying values of portfolio management costs. While irrelevant in the case of the optimal plan, this parameter is found to have very little impact on the magnitude of our results. As a matter of fact, the introduction of financial intermediation costs is more a technical trick allowing us to pin down a unique steady state of the economy under incomplete financial markets than an important assumption in terms of our results. The sensitivity analysis reveals that modifying the value of this parameter does not really affect our results since welfare gains range from $0.019 \%$ to $0.014 \%$ when $\chi$ ranges from 0 to 0.01 , which corresponds to an average annual interest rate premium varying from nearly $0 \%$ to $4 \%$.

(vii): The persistence parameter $\rho_{a}$ has a negative impact on welfare gains associated with incomplete financial markets. Higher persistence generates less incentives for agents to smooth their level consumption in time after asymmetric shocks and enhances their incentives to adjust permanently. Since our results builds on a mechanism relying on differences in terms of consumption smoothing, its importance decreases when the persistence of shocks increases and the argument tends to vanish as $\rho_{a}$ gets closer to unity.

Fig. 5. Welfare gains for different patterns of asymmetric nominal rigidities.

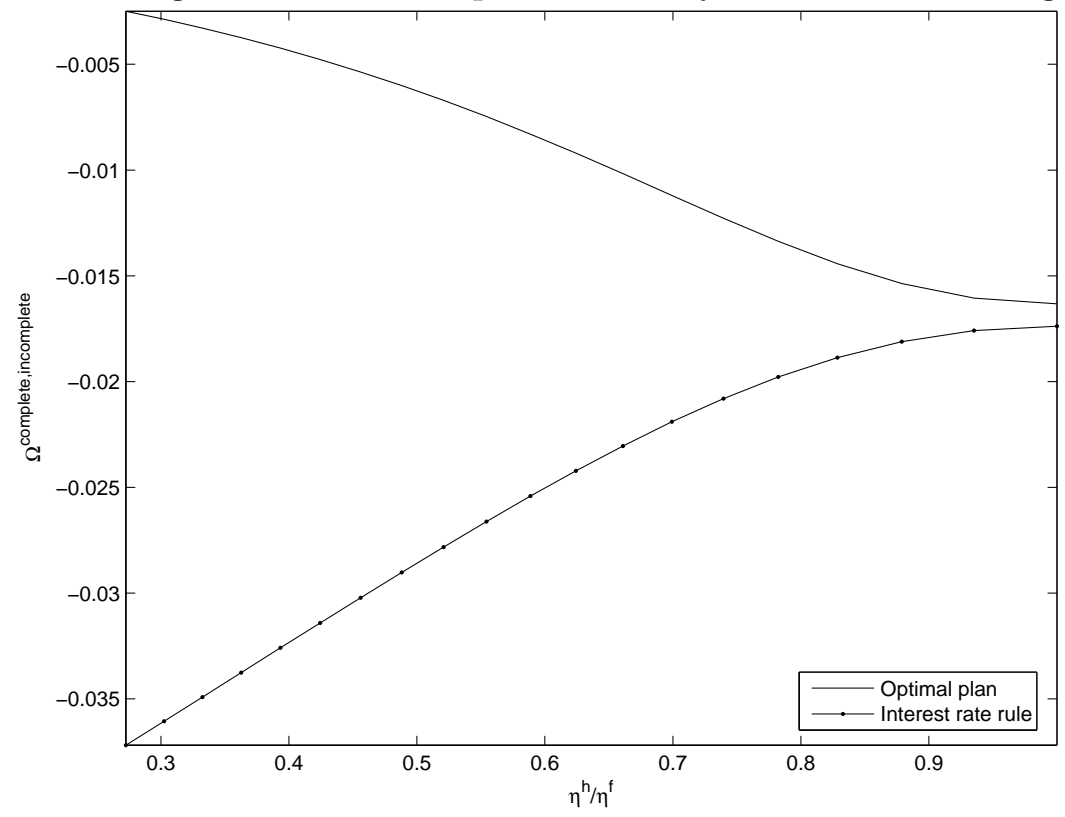

(viii): Finally, Figure 5 shows the evolution of welfare gains associated to financial 
markets incompleteness in the case of asymmetric nominal rigidities in the monetary union. In the spirit of Benigno [2004], we vary the relative duration of pricing contracts $\left(\eta^{h}\right.$ relative to $\left.\eta^{f}\right)$ while preserving a constant aggregate level of nominal rigidities in the currency area. ${ }^{5}$ While asymmetric nominal rigidities preserve the sign of the result both in the case of the optimal plan and Taylor-type monetary policy rule, asymmetries in the pattern of nominal rigidities $\left(\eta^{h} / \eta^{f}\right.$ being more distant from one) imply lower welfare gains of financial markets incompleteness under the optimal plan and higher welfare gains under Taylor-type monetary policy rules.

5 We make use of the following relation between price contracts durations, $\left(1-\eta^{h}\right)^{-\frac{1}{2}}(1-$ $\left.\eta^{f}\right)^{-\frac{1}{2}}=(1-\eta)^{-1}$. 


\section{Conclusion}

This paper considers a currency area model in which each country is specialized in the production of a bundle of goods. Goods are traded, but there can be home bias in consumption. Prices are sticky. The model follows from Benigno [2004] with some modifications. In particular, a departure from a unitary intratemporal elasticity of substitution de-couples complete from incomplete markets. The complete market model with state-contingent securities is compared to an incomplete market model in which only one nominal bond is traded. When prices are sticky, relative prices are also sticky, so a currency area is a second-best world. The question that this paper asks is whether having completeness of financial markets improves welfare. The answer is no. In a second-best world like a currency area, completing financial markets does not reach the first best. Thus, within a second-best world completing the financial markets might not be welfare improving with respect to a world in which markets are incomplete. On top of this, we show that with incomplete markets the volatility of the inflation rate is even lower than under complete markets and that there are substantial gains from not having complete markets. The main message of the paper is interesting and has interesting policy implications: in a second best, more financial integration might not be welfare improving.

\section{References}

Backus, D.K., P.J. Kehoe, and F. Kydland, International Real Business Cycles, in T. Cooley, editor, Frontiers of Business Cycle Research, Princeton, New-Jersey: Princeton University Press, 1995, chapter 11.

Beetsma, R. and H. Jensen, Monetary and fiscal policy interactions in a micro-founded model of a monetary union, Journal of International Economics, 2005, 67 (2), 320-352.

Benigno, P., Optimal Monetary Policy in a Currency Area, Journal of International Economics, 2004, 63 (3), 293-320.

, Price Stability with Imperfect Financial Integration, manuscript 2007.

and M. Woodford, Inflation Stabilization and Welfare: The Case of a Distorted Steady

State, Journal of the European Economic Association, 2005, 3 (6), 1185-1236.

_ _ and _ _ Optimal taxation in an RBC model: A linear-quadratic approach, Journal of Economic Dynamics and Control, 2006, 30 (9-10), 1445-1489.

Calvo, G., Staggered Contracts and Exchange Rate Policy, in J. Frenkel, editor, The Economics of Flexible Exchange Rates, Chicago: University of Chicago Press, 1983.

Canzoneri, M. and D. Henderson, Monetary Policy in Interdependent Economies: A GameTheoretic Approach, Cambridge: The M.I.T. Press, 1991. 
R. Cumby, and B. Diba, The Cost of Nominal Inertia in NNS Models, Journal of Money, Credit and Banking, 2007, 39 (7), 1563-1588.

Cole, H. and M. Obstfeld, Commodity trade and international risk sharing : How much do financial markets matter?, Journal of Monetary Economics, 1991, 28 (1), 3-24.

Corsetti, G., Openness and the Case for Flexible Exchange Rates, Research in Economics, 2006, 60 (1), 1-21.

Faia, E., Finance and International Business Cycles, Journal of Monetary Economics, 2007, 54 (4), 1018-1034.

Gali, J. and T. Monacelli, Monetary Policy and Exchange Rate Volatility in a Small Open Economy, Review of Economic Studies, 2005, 72, 707-34.

Harrigan, J., OECD Imports and Trade Barriers in 1983, Journal of International Economics, 1993, 35 (1-2), 99-111.

Kim, J. and S. H. Kim, Spurious Welfare Reversals in International Business Cycle Models, Journal of International Economics, 2003, 60 (2), 471-500.

, and A. Levin, Patience, persistence, and welfare costs of incomplete markets in open economies, Journal of International Economics, 2003, 61 (2), 385-396.

Rotemberg, J. and M. Woodford, An Optimization-Based Econometric Framework for the Evaluation of Monetary Policy, in Bernanke Ben S. and Julio J. Rotemberg, editors, NBER Macroeconomics Annual, 1997.

Schmitt-Grohe, S. and M. Uribe, Closing Small Open Economy Models, Journal of International Economics, 2003, 61 (1), 63-85.

Van Wincoop, E., How big are potential gains from international risksharing, Journal of International Economics, 1999, 47, 109-135.

Woodford, M., Optimal Interest-rate Smoothing, Review of Economic Studies, 2003, 70 (4), $861-86$. 


\section{Appendix}

The natural equilibrium

We define the natural (Pareto-efficient) equilibrium as the economic equilibrium arising when prices are flexible under complete asset markets, i.e. $\eta^{h}=\eta^{f}=0$ and $\chi=0$.

We firstly derive the natural path of aggregate variables, defined as,

$$
x_{t}^{u}=\frac{1}{2}\left(x_{t}^{h}+x_{t}^{f}\right)
$$

Using the pricing equations, $p_{h, t}=w_{t}^{h}-a_{t}^{h}$ and $p_{f, t}=w_{t}^{f}-a_{t}^{f}$, and adding them,

$$
w_{t}^{u}-p_{t}^{u}=a_{t}^{u}
$$

Using the aggregate leisure-consumption arbitrage,

$$
\psi n_{t}^{u}+\sigma c_{t}^{u}=w_{t}^{u}-p_{t}^{u}
$$

the aggregate production function,

$$
y_{t}^{u}=a_{t}^{u}+n_{t}^{u},
$$

and the aggregate equilibrium of goods markets,

$$
y_{t}^{u}=c_{t}^{u}
$$

we get the natural path of the aggregate consumption, which also equals the aggregate output,

$$
\widetilde{y}_{t}^{u}=\widetilde{c}_{t}^{u}=\frac{1+\psi}{\sigma+\psi} a_{t}^{u} .
$$

Combining the previous expression with the aggregate Euler equation, we determine the natural equilibrium interest rate,

$$
\frac{\delta}{1+\delta} \widetilde{r}_{t}=\sigma E_{t}\left\{\widetilde{c}_{t+1}^{u}\right\}-\sigma \widetilde{c}_{t}^{u}
$$

implying,

$$
\widetilde{r}_{t}=\frac{\sigma(1+\delta)(1+\psi)}{\delta(\sigma+\psi)}\left(E_{t}\left\{a_{t+1}^{u}\right\}-a_{t}^{u}\right)
$$


We now turn to the natural path of relative variables, defined as,

$$
x_{t}^{r}=\frac{1}{2}\left(x_{t}^{f}-x_{t}^{h}\right) .
$$

In the natural equilibrium, the financial market is complete, implying,

$$
2 \sigma \widetilde{c}_{t}^{r}=-(1-2 \alpha) \widetilde{s}_{t}
$$

Combining this expression with the relative leisure-consumption arbitrage condition, we get,

$$
\psi \widetilde{n}_{t}^{r}-\frac{1-2 \alpha}{2} \widetilde{s}_{t}=\widetilde{w}_{t}^{r}-\widetilde{p}_{t}^{r}
$$

Using the definition of terms-of-trade,

$$
\widetilde{p}_{t}^{r}=\frac{(1-2 \alpha)}{2} \widetilde{s}_{t}
$$

the relative leisure-consumption arbitrage condition becomes,

$$
\psi \widetilde{n}_{t}^{r}=\widetilde{w}_{t}^{r}
$$

The relative pricing equation yields,

$$
\widetilde{s}_{t}=\widetilde{p}_{f, t}-\widetilde{p}_{h, t}=2\left(\widetilde{w}_{t}^{r}-\widetilde{a}_{t}^{r}\right),
$$

which, combined with the previous condition, yields,

$$
\psi \widetilde{n}_{t}^{r}=\frac{1}{2} \widetilde{s}_{t}+a_{t}^{r}
$$

On the other hand, the risk-sharing condition, combined with the relative equilibrium condition on goods markets yields,

$$
\widetilde{y}_{t}^{r}=-\varpi_{\alpha} \widetilde{s}_{t},
$$

where $\varpi_{\alpha}=\frac{(1-2 \alpha)^{2}+4 \sigma \mu \alpha(1-\alpha)}{2 \sigma}$.

Using the relative production function,

$$
\widetilde{n}_{t}^{r}=\widetilde{y}_{t}^{r}-a_{t}^{r},
$$

we get,

$$
\widetilde{n}_{t}^{r}=-\varpi_{\alpha} \widetilde{s}_{t}-a_{t}^{r}
$$


Combining (19) and (20), we get the natural path of terms-of-trade,

$$
\widetilde{s}_{t}=-\frac{2(1+\psi)}{\left(1+2 \psi \varpi_{\alpha}\right)} a_{t}^{r}
$$

Summing up, using the relative equilibrium condition of goods markets to get $\widetilde{c}_{t}^{r}$, and the relative production function to get $\widetilde{n}_{t}^{r}$, we have,

$$
\begin{aligned}
\widetilde{s}_{t} & =-\frac{2(1+\psi)}{1+2 \psi \varpi_{\alpha}} a_{t}^{r}, \\
\widetilde{c}_{t}^{r} & =\frac{(1+\psi)(1-2 \alpha)}{\sigma\left(1+2 \psi \varpi_{\alpha}\right)} a_{t}^{r}, \\
\widetilde{n}_{t}^{r} & =\frac{2 \varpi_{\alpha}-1}{\left(1+2 \psi \varpi_{\alpha}\right)} a_{t}^{r} .
\end{aligned}
$$

The quadratic welfare-based loss function

The welfare criterion writes,

$$
\begin{aligned}
\omega_{T} & =E_{0} \sum_{t=0}^{T} \beta^{t}\left\{\int_{0}^{1}\left(\frac{1}{2} U_{t}^{h}(j)+\frac{1}{2} U_{t}^{f}(j)\right) d j\right\} \\
& =E_{0} \sum_{t=0}^{T} \beta^{t}\left\{\int_{0}^{1}\left(U_{C, t}^{u}(j)-U_{N, t}^{u}(j)\right) d j\right\} .
\end{aligned}
$$

After using the symmetry among agents, we get

$$
\begin{aligned}
& U_{C, t}^{u}(j)=U_{C, t}^{u}=\frac{1}{2(1-\sigma)}\left(C_{t}^{h}\right)^{1-\sigma}+\frac{1}{2(1-\sigma)}\left(C_{t}^{f}\right)^{1-\sigma} \\
& U_{N, t}^{u}(j)=U_{N, t}^{u}=\frac{1}{2(1+\psi)}\left(N_{t}^{h}\right)^{1+\psi}+\frac{1}{2(1+\psi)}\left(N_{t}^{f}\right)^{1+\psi}
\end{aligned}
$$

We begin the derivation by taking a second order approximation of $U_{N, t}^{u}$,

$$
U_{N, t}^{u} \simeq \frac{N^{1+\psi}}{1+\psi}+N^{1+\psi}\left(n_{t}^{u}+\frac{1+\psi}{2}\left(\left[n_{t}^{u}\right]^{2}+\left[n_{t}^{r}\right]^{2}\right)\right)+O\left(\left\|\xi^{3}\right\|\right)
$$

Recalling that the approximation is taken around the steady state assuming $\left[a_{t}^{i}\right]^{2}=0$ (see Benigno and Woodford [2005]), second order approximations of production func- 
tions write,

$$
\begin{aligned}
& n_{t}^{h}+\frac{1}{2}\left(a_{t}^{h}+n_{t}^{h}\right)^{2}=y_{t}^{h}+d p_{t}^{h}+t . i . p+O\left(\left\|\xi^{3}\right\|\right), \\
& n_{t}^{f}+\frac{1}{2}\left(a_{t}^{f}+n_{t}^{f}\right)^{2}=y_{t}^{f}+d p_{t}^{f}+t . i . p+O\left(\left\|\xi^{3}\right\|\right),
\end{aligned}
$$

where t.i.p gathers terms independent of the policy problem, and where,

$$
d p_{t}^{i}=\frac{\theta}{2} \operatorname{var}\left(p_{i, t}\right)
$$

implying $\left(d p_{t}^{i}\right)^{2} \in O\left(\left\|\xi^{3}\right\|\right)$.

Combining these expressions, we get,

$n_{t}^{u}+\frac{1}{2}\left(n_{t}^{u}\right)^{2}+\frac{1}{2}\left(n_{t}^{r}\right)^{2}+\frac{1}{2} a_{t}^{h} n_{t}^{h}+\frac{1}{2} a_{t}^{f} n_{t}^{f}=y_{t}^{u}+\frac{1}{2}\left(y_{t}^{u}\right)^{2}+\frac{1}{2}\left(y_{t}^{r}\right)^{2}+\frac{\theta}{4} \operatorname{var}\left(p_{h, t}\right)+\frac{\theta}{4} \operatorname{var}\left(p_{f, t}\right)+t . i . p+O\left(\left\|\xi^{3}\right\|\right)$.

The previous expression is then plugged in the approximation of $U_{N, t}^{u}$,

$$
\begin{aligned}
U_{N, t}^{u} & \simeq N^{1+\psi}\left\{y_{t}^{u}+\frac{1}{2}\left(y_{t}^{u}\right)^{2}+\frac{1}{2}\left(y_{t}^{r}\right)^{2}-\frac{1}{2} a_{t}^{h} n_{t}^{h}-\frac{1}{2} a_{t}^{f} n_{t}^{f}+\frac{\theta}{4} \operatorname{var}\left(p_{h, t}\right)+\frac{\theta}{4} \operatorname{var}\left(p_{f, t}\right)\right. \\
& \left.+\frac{\psi}{2}\left(n_{t}^{u}\right)^{2}+\frac{\psi}{2}\left(n_{t}^{r}\right)^{2}\right\}+t . i . p+O\left(\left\|\xi^{3}\right\|\right) .
\end{aligned}
$$

Now focusing on $U_{C, t}^{u}$, we compute a second order approximation of $U_{C, t}^{u}$,

$$
U_{C, t}^{u} \simeq \frac{C^{1-\sigma}}{1-\sigma}+C^{1-\sigma}\left(c_{t}^{u}+\frac{1-\sigma}{2}\left(\left(c_{t}^{u}\right)^{2}+\left(c_{t}^{r}\right)^{2}\right)\right)+O\left(\left\|\xi^{3}\right\|\right) .
$$

A second order approximation of final goods markets equilibria gives,

$$
\begin{aligned}
y_{t}^{h}+\frac{1}{2}\left(y_{t}^{h}\right)^{2} & =(1-\alpha)\left(c_{t}^{h}+\mu \alpha s_{t}+\frac{1}{2}\left(c_{t}^{h}+\alpha \mu s_{t}\right)^{2}\right) \\
& +\alpha\left(c_{t}^{f}+\mu(1-\alpha) s_{t}+\frac{1}{2}\left(c_{t}^{f}+\mu(1-\alpha) s_{t}\right)^{2}\right) \\
& + \text { t.i.p }+O\left(\left\|\xi^{3}\right\|\right), \\
y_{t}^{f}+\frac{1}{2}\left(y_{t}^{f}\right)^{2} & =(1-\alpha)\left(c_{t}^{f}-\mu \alpha s_{t}+\frac{1}{2}\left(c_{t}^{f}-\mu \alpha s_{t}\right)^{2}\right) \\
& +\alpha\left(c_{t}^{h}-\mu(1-\alpha) s_{t}+\frac{1}{2}\left(c_{t}^{h}-(1-\mu \alpha) s_{t}\right)^{2}\right) \\
& +t . i . p+O\left(\left\|\xi^{3}\right\|\right) .
\end{aligned}
$$


Combining these expressions, we get,

$$
\begin{aligned}
y_{t}^{u}+\frac{1}{2}\left(y_{t}^{u}\right)^{2}+\frac{1}{2}\left(y_{t}^{r}\right)^{2} & =c_{t}^{u}+\frac{1}{2}\left(c_{t}^{u}\right)^{2}+\frac{1}{2}\left(c_{t}^{r}\right)^{2}+\frac{\mu \alpha(1-\alpha)}{2}\left(s_{t}\right)^{2} \\
& + \text { t.i.p }+O\left(\left\|\xi^{3}\right\|\right)
\end{aligned}
$$

or,

$$
\begin{aligned}
c_{t}^{u}+\frac{1}{2}\left(c_{t}^{u}\right)^{2}+\frac{1}{2}\left(c_{t}^{r}\right)^{2} & =y_{t}^{u}+\frac{1}{2}\left(y_{t}^{u}\right)^{2}+\frac{1}{2}\left(y_{t}^{r}\right)^{2}-\frac{\mu \alpha(1-\alpha)}{2}\left(s_{t}\right)^{2} \\
& + \text { t.i.p }+O\left(\left\|\xi^{3}\right\|\right) .
\end{aligned}
$$

The previous expression is then plugged in the approximation of $U_{C, t}^{u}$,

$U_{C, t}^{u} \simeq C^{1-\sigma}\left\{y_{t}^{u}+\frac{1}{2}\left(y_{t}^{u}\right)^{2}+\frac{1}{2}\left(y_{t}^{r}\right)^{2}-\frac{\mu \alpha(1-\alpha)}{2}\left(s_{t}\right)^{2}-\frac{\sigma}{2}\left(c_{t}^{u}\right)^{2}-\frac{\sigma}{2}\left(c_{t}^{r}\right)^{2}\right\}+t . i \cdot p+O\left(\left\|\xi^{3}\right\|\right)$.

Now combining $U_{N, t}^{u}$ and $U_{C, t}^{u}$, we get,

$$
\begin{aligned}
U_{t}^{u} & =U_{C, t}^{u}-U_{N, t}^{u} \simeq C^{1-\sigma}\left\{y_{t}^{u}+\frac{1}{2}\left(y_{t}^{u}\right)^{2}+\frac{1}{2}\left(y_{t}^{r}\right)^{2}-\frac{\mu \alpha(1-\alpha)}{2}\left(s_{t}\right)^{2}-\frac{\sigma}{2}\left(c_{t}^{u}\right)^{2}-\frac{\sigma}{2}\left(c_{t}^{r}\right)^{2}\right. \\
& -N^{1+\psi}\left\{y_{t}^{u}+\frac{1}{2}\left(y_{t}^{u}\right)^{2}+\frac{1}{2}\left(y_{t}^{r}\right)^{2}+\frac{\theta}{4} \operatorname{var}\left(p_{h, t}\right)+\frac{\theta}{4} \operatorname{var}\left(p_{f, t}\right)-\frac{1}{2} a_{t}^{h} n_{t}^{h}-\frac{1}{2} a_{t}^{f} n_{t}^{f}\right. \\
& \left.+\frac{\psi}{2}\left(n_{t}^{u}\right)^{2}+\frac{\psi}{2}\left(n_{t}^{r}\right)^{2}\right\}+t . i \cdot p+O\left(\left\|\xi^{3}\right\|\right) .
\end{aligned}
$$

Using the fact that,

$$
N^{1+\psi}=\frac{Y}{A} N^{\psi}=Y C^{-\sigma}=C^{1-\sigma}
$$

we get,

$$
\begin{aligned}
U_{t}^{u} & \simeq C^{1-\sigma}\left\{-\frac{\mu \alpha(1-\alpha)}{2}\left(s_{t}\right)^{2}-\frac{\sigma}{2}\left(\left(c_{t}^{u}\right)^{2}+\left(c_{t}^{r}\right)^{2}\right)+\frac{1}{2} a_{t}^{h} n_{t}^{h}+\frac{1}{2} a_{t}^{f} n_{t}^{f}\right. \\
& \left.-\frac{\psi}{2}\left(\left(n_{t}^{u}\right)^{2}+\left(n_{t}^{r}\right)^{2}\right)-\frac{\theta}{4} \operatorname{var}\left(p_{h, t}\right)-\frac{\theta}{4} \operatorname{var}\left(p_{f, t}\right)\right\}+t . i . p+O\left(\left\|\xi^{3}\right\|\right) .
\end{aligned}
$$

Using,

$$
\begin{aligned}
n_{t}^{u} & =y_{t}^{u}-a_{t}^{u}, \\
y_{t}^{u} & =c_{t}^{u},
\end{aligned}
$$


we get,

$$
\begin{aligned}
U_{t}^{u} & \simeq C^{1-\sigma}\left\{-\frac{\mu \alpha(1-\alpha)}{2}\left(s_{t}\right)^{2}-\frac{\theta}{4} \operatorname{var}\left(p_{h, t}\right)-\frac{\theta}{4} \operatorname{var}\left(p_{f, t}\right)\right. \\
& -\frac{\sigma}{2}\left(c_{t}^{u}\right)^{2}-\frac{\sigma}{2}\left(c_{t}^{r}\right)^{2}-\frac{\psi}{2}\left(n_{t}^{r}\right)^{2}+\frac{1}{2} a_{t}^{h} n_{t}^{h}+\frac{1}{2} a_{t}^{f} n_{t}^{f} \\
& \left.-\frac{\psi}{2}\left(\left(c_{t}^{u}\right)^{2}-2 c_{t}^{u} a_{t}^{u}\right)\right\}+t . i \cdot p+O\left(\left\|\xi^{3}\right\|\right) .
\end{aligned}
$$

We then manage to make the term $\left[c_{t}^{u}-\widetilde{c}_{t}^{u}\right]^{2}$ appear in the welfare criterion, we get,

$$
\begin{aligned}
U_{t}^{u} & \simeq \frac{C^{1-\sigma}}{2}\left\{-\mu \alpha(1-\alpha)\left(s_{t}\right)^{2}-\frac{\theta}{2} \operatorname{var}\left(p_{h, t}\right)-\frac{\theta}{2} \operatorname{var}\left(p_{f, t}\right)\right. \\
& -(\sigma+\psi)\left(c_{t}^{u}-\widetilde{c}_{t}^{u}\right)^{2}-2(\sigma+\psi) c_{t}^{u} \widetilde{c}_{t}^{u}+2 \psi c_{t}^{u} a_{t}^{u} \\
& \left.-\sigma\left(c_{t}^{r}\right)^{2}-\psi\left(n_{t}^{r}\right)^{2}+a_{t}^{h} n_{t}^{h}+a_{t}^{f} n_{t}^{f}\right\}+t . i . p+O\left(\left\|\xi^{3}\right\|\right) .
\end{aligned}
$$

Using the definition of $\widetilde{c}_{t}^{u}$,

$$
\widetilde{c}_{t}^{u}=\frac{1+\psi}{\sigma+\psi} a_{t}^{u}
$$

we get,

$$
\begin{aligned}
U_{t}^{u} & \simeq \frac{C^{1-\sigma}}{2}\left\{-\mu \alpha(1-\alpha)\left(s_{t}\right)^{2}-\frac{\theta}{2} \operatorname{var}\left(p_{h, t}\right)-\frac{\theta}{2} \operatorname{var}\left(p_{f, t}\right)\right. \\
& -(\sigma+\psi)\left(c_{t}^{u}-\widetilde{c}_{t}^{u}\right)^{2}-2(1+\psi) c_{t}^{u} a_{t}^{u}+2 \psi c_{t}^{u} a_{t}^{u} \\
& \left.-\sigma\left(c_{t}^{r}\right)^{2}-\psi\left(n_{t}^{r}\right)^{2}+a_{t}^{h} n_{t}^{h}+a_{t}^{f} n_{t}^{f}\right\}+t . i . p+O\left(\left\|\xi^{3}\right\|\right) .
\end{aligned}
$$

We then use the following relation,

$$
\begin{aligned}
a_{t}^{h} n_{t}^{h}+a_{t}^{f} n_{t}^{f} & =2 n_{t}^{u} a_{t}^{u}+2 n_{t}^{r} a_{t}^{r}, \\
& =2 c_{t}^{u} a_{t}^{u}+2 n_{t}^{r} a_{t}^{r}+\text { t.i.p }
\end{aligned}
$$

to get,

$$
\begin{aligned}
U_{t}^{u} & \simeq \frac{C^{1-\sigma}}{2}\left\{-\mu \alpha(1-\alpha)\left(s_{t}\right)^{2}-\frac{\theta}{2} \operatorname{var}\left(p_{h, t}\right)-\frac{\theta}{2} \operatorname{var}\left(p_{f, t}\right)\right. \\
& \left.-(\sigma+\psi)\left(c_{t}^{u}-\widetilde{c}_{t}^{u}\right)^{2}-\sigma\left(c_{t}^{r}\right)^{2}-\psi\left(n_{t}^{r}\right)^{2}+2 n_{t}^{r} a_{t}^{r}\right\} \\
& + \text { t.i.p+o }\left(\left\|\xi^{3}\right\|\right) .
\end{aligned}
$$

In the next step, we show that $2 n_{t}^{r} a_{t}^{r}$ can be expressed as a function of $\widetilde{s}_{t}, \widetilde{c}_{t}^{r}, n_{t}^{r}$. We 
start with the following decomposition,

$$
2 n_{t}^{r} a_{t}^{r}=\frac{2(1+\psi)}{1+2 \psi \varpi_{\alpha}} n_{t}^{r} a_{t}^{r}+\underbrace{\left(2 \psi \frac{2 \varpi_{\alpha}-1}{1+2 \psi \varpi_{\alpha}} a_{t}^{r}\right)}_{2 \psi \widetilde{n}_{t}^{r}} n_{t}^{r}
$$

Using,

$$
\begin{aligned}
n_{t}^{r} & =y_{t}^{r}-a_{t}^{r}, \\
y_{t}^{r} & =(1-2 \alpha) c_{t}^{r}-2 \mu \alpha(1-\alpha) s_{t},
\end{aligned}
$$

and using natural equilibrium expressions of $\widetilde{s}_{t}, \widetilde{c}_{t}^{r}, \widetilde{n}_{t}^{r}$,

$$
\begin{aligned}
\widetilde{s}_{t} & =-\frac{2(1+\psi)}{1+2 \psi \varpi_{\alpha}} a_{t}^{r}, \\
\widetilde{c}_{t}^{r} & =\frac{(1+\psi)(1-2 \alpha)}{\sigma\left(1+2 \psi \varpi_{\alpha}\right)} a_{t}^{r}, \\
\widetilde{n}_{t}^{r} & =\frac{2 \varpi_{\alpha}-1}{1+2 \psi \varpi_{\alpha}} a_{t}^{r},
\end{aligned}
$$

we get,

$$
2 n_{t}^{r} a_{t}^{r}=2 c_{t}^{r} \underbrace{\left(\frac{(1+\psi)(1-2 \alpha)}{1+2 \psi \varpi_{\alpha}} a_{t}^{r}\right)}_{\widetilde{\sigma_{t}^{r}}}-2 \mu \alpha(1-\alpha) s_{t} \underbrace{\left(\frac{2(1+\psi)}{1+2 \psi \varpi_{\alpha}} a_{t}^{r}\right)}_{-\widetilde{s}_{t}}+2 \psi \widetilde{n}_{t}^{r} n_{t}^{r}+t . i . p,
$$

or,

$$
2 n_{t}^{r} a_{t}^{r}=2 \sigma \widetilde{c}_{t}^{r} c_{t}^{r}+2 \psi \widetilde{n}_{t}^{r} n_{t}^{r}+2 \mu \alpha(1-\alpha) \widetilde{s}_{t} s_{t}+\text { t.i.p. }
$$

Plugging this relation in the welfare criterion, we get,

$$
\begin{aligned}
U_{t}^{u} & \simeq \frac{C^{1-\sigma}}{2}\left\{-\frac{\theta}{2} \operatorname{var}\left(p_{h, t}\right)-\frac{\theta}{2} \operatorname{var}\left(p_{f, t}\right)-\mu \alpha(1-\alpha)\left(\widehat{s}_{t}\right)^{2}\right. \\
& \left.-(\sigma+\psi)\left(\widehat{c}_{t}^{u}\right)^{2}-\sigma\left(\widehat{c}_{t}^{r}\right)^{2}-\psi\left(\widehat{n}_{t}^{r}\right)^{2}\right\}+t . i . p+O\left(\left\|\xi^{3}\right\|\right)
\end{aligned}
$$

where $\widehat{x}_{t}=x_{t}-\widetilde{x}_{t}$ are variables expressed in deviation to their natural equilibrium expressions.

Actualizing and summing, we get,

$$
\omega_{T}=E_{0} \sum_{t=0}^{T} \beta^{t}\left\{U_{t}^{u}\right\}
$$


Following Woodford [2003] we know that,

$$
\sum_{t=0}^{T} \beta^{t} \operatorname{var}_{i}\left(p_{i, t}\right)=\sum_{t=0}^{T} \beta^{t} \frac{\pi_{i, t}^{2}}{k^{i}}
$$

where $k^{i}=\frac{\left(1-\eta^{i} \beta\right)\left(1-\eta^{i}\right)}{\eta^{i}}$.

Summing-up, the welfare criterion criterion writes,

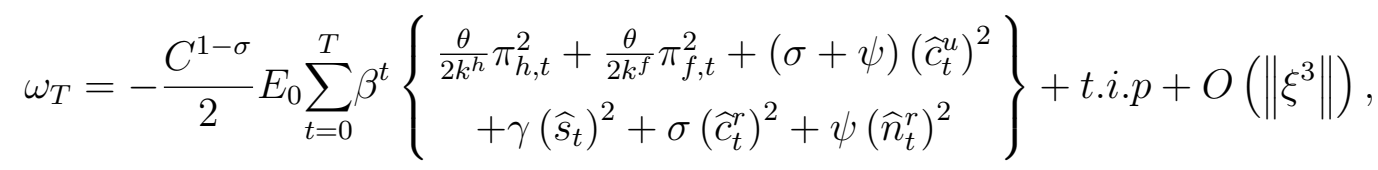

where $\gamma=\mu \alpha(1-\alpha)$, t.i.p gathers terms independent of the problem and $O\left(\left\|\xi^{3}\right\|\right)$ high order terms. Since $C^{1-\sigma}=1$, we finally get,

$\omega_{T}=-\frac{1}{2} E_{0} \sum_{t=0}^{T} \beta^{t}\left\{\frac{\theta}{2 k^{h}} \pi_{h, t}^{2}+\frac{\theta}{2 k^{f}} \pi_{f, t}^{2}+(\sigma+\psi)\left(\widehat{c}_{t}^{u}\right)^{2}+\gamma\left(\widehat{s}_{t}\right)^{2}+\sigma\left(\widehat{c}_{t}^{r}\right)^{2}+\psi\left(\widehat{n}_{t}^{r}\right)^{2}\right\}+t . i \cdot p+O\left(\left\|\xi^{3}\right\|\right)$. 